\title{
Detecting of a Global and Caribbean Climate Change
}

\author{
Nazario D. Ramirez-Beltran, Joan Manuel Castro and Oswaldo Julca \\ University of Puerto Rico at Mayaguez, \\ Puerto Rico
}

\section{Introduction}

Weather is defined as what is happening to the atmosphere at any given time while climate is what would be expected to occur at any given time of the year based on many years of meteorological observations. Change in climate constitutes shifts in meteorological conditions lasting a few years or longer. The climate change can occur in a single meteorological variable or in a group of variables affecting a region or the entire Earth (Burroughs, 2001). It is expected that a climate change can be expressed by the behaviour of time series of meteorological variables and in this study, a meteorological variable that expresses a climate change is called a climate indicator. Over the years, the climate of the Earth has changed due to natural or anthropogenic factors, and the research community is concentrating on the identification of the evidences of these changes. However, there are some uncertainties about the occurrence of a significant climate change and especially the time when the changes have become evident. The main purpose of this chapter is to introduce a statistical test to determine when a significant climate change has occurred assuming that a climate indicator is available. A climate indicator is a meteorological variable that reveals the climate of a region or a given part of the Earth. The suggested statistical test will be applied to detect climate changes at the global and Caribbean scale using several climatic indicators.

During the last 140 years the Earth has been experimented several climate changes, which have been documented by several researchers (Huntingford et al., 2006; Hansen 2005; Easterling et al., 2000; Battisti el al., 1997; She and Krueger 2004; and Barnett et al., 1999). For example, Easterling et al., (1997) reported that the global mean surface air temperature has risen about $0.5^{\circ} \mathrm{C}$ during the 20th century. A large part of the world ocean has shown coherent changes of heat content during the last 50 years (Leuliette et al., 2004). Frich et al., (2002) claim that during the second half of the 20th century the world has become both warmer and wetter for global land areas and currently wet periods produce significantly larger rainfall than a few decades ago. These observed extreme events are in line with the expected changes due to the new greenhouse conditions. Global warming is affecting human lives, and in particular is severely impacting the agriculture forestry and in general the economy (Salinger 2005). For instance, Easterling et al., (2000) pointed out that in the United States since 1987 more than 360 weather events have produced losses in excess of \$5 million each event with several catastrophic consequences. The temperature in globe has increased during the last 140 years, because that the number of heat waves has increased (Schar et al., 2004; Changnon et al., 2000). Global warming is a real process that is leading to 
catastrophic consequences. It has been documented that the global warming is mainly due to anthropogenic factors (Huntingford et al., 2006; Hansen 2005; Easterling et al., 2000). The International Project of Climate Change (IPCC) has established that most of the observed increment in global temperatures since the mid-20th century is very likely due to the observed increase in anthropogenic greenhouse gas concentrations. The anthropogenic activities that affect the global warming are the emission of greenhouse gases and changes in land use, such as urbanization and agriculture. Recent simulation results have shown that the global warming during the last 20th century cannot only be explained by external forces, but also by natural variability that play an important role (Huntingford 2006, IPCC 2001, IPCC 2007). Battist et al. (1997) pointed out that the global warming may be attributed to natural variability, which can be observed in the energy transported by the atmosphere and ocean circulation. Kruger (2004) and Barnett et al., (1999) have established that the natural variability is due to volcanic eruption (Robock A., 2000), and the solar flux variability. Atmospheric dynamics simulations at global and regional scales have been conducted over different scenarios to predict the most likely future climate impacts (IPCC 2001; Angeles 2005; Huntingford et al., 2006; Hansen 2005). Stott and Ketteborough (2002) claim that predicting Earth surface temperature is almost impossible since the anthropogenic and the natural variability include a large amount of uncertainties that may be difficult to predict. However, Angeles et al., (2007) uses global outputs and a regional atmospheric model to project that during the next five decades there will be large concentrations of rainfall episodes in smaller areas across the Caribbean basin.

Climate change detection and attribution techniques usually apply global or regional circulation models and/or statistical techniques to detect climate changes (Easterling et al., 1997, 2000; Barnett et al., 1999; Schar et al., 2004; Smith et al., 2002; Santer et al., 2005; Meehl et al., 2004; Menne et al., 2005; Tomé and Miranda 2004; Feldstein 2002; IPCC 2001; Smith et al., 2002). A climate change may be expressed as a change in the mean or in the autocorrelation function of the underlying climate indicator. A statistical algorithm for climate change detection is introduced here with the intention of providing a tool to determine when a significant climate change has occurred. The algorithm is based on determining when the mean of the underlying climate indicator exhibits a significant deviation from a selected reference. The algorithm will divide the climate indicator in two parts the reference data and the testing data. The reference data will be used to identify the deterministic and stochastic components of the reference data, and the testing part is used to measure the deviation from the reference. Thus if a significant deviation from the reference data is found a climate change is detected at the identified point in time. The algorithm can detect climate changes that occur in the trend, in the seasonal or in the stochastic component. A simulation technique was used to design a climate indicator with three components and a postulated change was used to validate the performance of the proposed test. Real climate indicators were also used to detect climate change. Regression techniques were used to model the trend and seasonal components, and a time series model was used to represent the stochastic component of real time series data. Climate changes at global and Caribbean scale were studied.

The second section of this chapter will present the basis of the proposed algorithm for detecting changes in a climate indicator. The third section presents a simulation exercise to illustrate the performance of the detection test. The fourth section will describe the data and sources of information, as well as some applications of the test at the Global and Caribbean climate scale, and the last section will present some conclusions. 


\section{Methodology}

The deterministic components of a climate indicator, such as trend, and periodicity will be identified and removed from the data to estimate the stochastic component, which will be modelled by using a time series model. The identified time series model is also removed from the data to obtain a white noise process. Finally, a sequential statistical test will be implemented to detect whether or not a significant deviation from the white noise process has occurred. The algorithm is based on the fact that if a climate indicator does not contain any climate change then the entire time series will behave as a white noise process. On the other hand, if a climate indicator involves a climate change the stochastic behaviour of the testing part will show that the underlying climate change caused a significant deviation from the white noise process. The algorithm includes six major steps: (1) collect the largest time series of a climate indicator; (2) divide the data sets in two parts: the first par will be called the reference data and the second part as the testing data; (3) identify periodicity and trend components based on the reference data, and remove periodicity and trend components from the entire time series and call the resulting time series the estimated of the stochastic component; (4) identify an autoregressive moving average (ARMA) model to the first part of the estimated stochastic component; (5) compute the ARMA fingerprint; and (6) use a sequential hypothesis testing procedure to determine whether or not a significant change has occurred on the mean or in the autocorrelation function of the process. This study will focus on detecting changes on the mean of the process, where the mean of the process may be a constant or a time dependent function.

\subsection{Step one: select a climate indicator}

It is assumed that climate properties of a given part of the world are expressed by a sequence of a meteorological variable, which we referred as a climate indicator. Thus, a climate indicator can be a time series of air temperature, sea level, rainfall, etc. It is required that the selected time series has no missing values and observations have been obtained at equal time intervals. The climate change can occur at different time scales and to be able to detect a climate change it is required to select a climate indicator that contains observations before and after the climate change. It is desirable that the time series will be large enough to identify the deterministic and stochastic components of the underlying meteorological process and leaving a significant part of data for testing. The length of the data will be established in step two.

\subsection{Step two: dividing the time series}

The time series will be divided into two parts. The first part will be called the reference data and the second part will be the testing data. The reference data will be used as a reference level to measure the deviation (if any) of the testing data with respect to the reference data. If the underlying time series is a periodic series, the length of the reference data must contain at least three times the length of the period. On the other hand, if the time series is not a periodic series, it is recommended that reference data would contain at least 50 observations. The reference data will be located on the left (older values of the series) and the testing part on the right hand side (more recent values) of the series. Typically, the reference data is located at the beginning of the time series; however, it could be placed in almost any part of the series as long as enough observations are available. The testing part will be at least 50 observations and will be used to measure whether or not there exists a 
significant change with respect to the reference data. It should be noted that the change detection test will depend on the meteorological properties of the selected reference and testing data, which can be expressed as follows:

Reference data:

$$
\left\{x_{t}, t=1,2, \ldots, m\right\}
$$

Testing data:

$$
\left\{\mathrm{x}_{\mathrm{t}}, \mathrm{t}=\mathrm{m}+1, \mathrm{~m}+2, \ldots, \mathrm{n}, \quad \mathrm{m} \geq 50, \text { and } \mathrm{n} \geq 2 \mathrm{~m}\right\}
$$

where $x_{t}$ represents the underlying climate indicator at time $t ; m$ is sample size of the reference data, and $\mathrm{n}$ is the total number of observations considered for climate change detection, and $\mathrm{n} \geq 2 \mathrm{~m}$.

\subsection{Step three: identifying the deterministic components}

A climate indicator may be stationary or a nonstationary process and consequently it may have deterministic and stochastic components. The deterministic component may be a trend and/or a periodic component. Thus, the reference data of the climate indicator may be expressed as follows:

$$
\mathrm{x}_{\mathrm{t}}=\mathrm{T}_{\mathrm{t}}+\mathrm{P}_{\mathrm{t}}+\mathrm{s}_{\mathrm{t}}, \quad \mathrm{t}=1, \ldots, \mathrm{m}
$$

where $T_{t}$ and $P_{t}$ are the deterministic trend and periodic components, respectively at time $t$, and $s_{t}$ is the stochastic components at time $t$. The trend component can be modeled by a polynomial in time and the periodic component by a sinusoidal function of time. The autocorrelation function and the periodogram of $x_{t}$ can be used to identify the trend and the periodic components; i. e., if the autocorrelation function dies out very fast, the underlying process is stationary and the process do not exhibit trend; otherwise, a trend should be identified. Regression techniques can be used to estimate the parameters of the trend and the sinusoidal function. The Fourier-based method or a more accurate method based on wavelet techniques (Nicolay, et al., 2010) can be used to estimate the size of the required periods. The trend and periodic components are removed from the original time series to estimate the stochastic component, $\hat{\mathrm{s}}_{\mathrm{t}}$.

$$
\widehat{\mathrm{s}}_{\mathrm{t}}=\mathrm{x}_{\mathrm{t}}-\widehat{\mathrm{T}}_{\mathrm{t}}-\widehat{\mathrm{P}}_{\mathrm{t}}, \quad \mathrm{t}=1, \ldots, \mathrm{n}
$$

where $\widehat{T}_{t}$ and $\widehat{P}_{t}$ are the estimates of the trend and periodic components, respectively. In time series analysis is customary to remove the trend and periodic components by using the appropriate difference operators. For example:

$$
\nabla^{\mathrm{d}} \mathrm{x}_{\mathrm{t}}=(1-\mathrm{B})^{\mathrm{d}} \mathrm{x}_{\mathrm{t}}
$$

where $\nabla^{d}$ is the difference-of-order $\mathrm{d}$ operator and $\mathrm{B}^{\mathrm{k}}$ is the backshift operator, which is defined as follows: $\mathrm{B}^{\mathrm{k}} \mathrm{x}_{\mathrm{t}}=\mathrm{x}_{\mathrm{t}-\mathrm{k}}$. The operator to remove periodicity can be written as follows:

$$
\nabla_{\mathrm{p}}^{\mathrm{D}} \mathrm{x}_{\mathrm{t}}=\left(1-\mathrm{B}^{\mathrm{p}}\right)^{\mathrm{D}} \mathrm{x}_{\mathrm{t}}
$$

where $\mathrm{D}$ is the order of seasonal difference and $\mathrm{p}$ is the period of the time series. Unfortunately, these operators cannot be applied in this case since the application of these operators will remove not only the trend and periodic components but also will remove the 
climate change signal; and consequently, these operators are not suitable for the purposes of detecting a climate change.

\subsection{Step four: identifying the stochastic component}

The first $\mathrm{m}$ values of the stochastic component, $\hat{\mathrm{s}}_{\mathrm{t}}$, are used to identify the autocorrelation structure of the time series. Most of the stochastic components of climate indicators are a sequence that can be represented by autoregressive moving average (ARMA) models (Box and Jenkins 1976). The reference data will be tested first to determine whether or not the reference data is an autocorrelated or a white noise process. If the underlying process is a white noise there is no need of removing the autocorrelation structure. On the other hand, if the autocorrelated structure of the reference data is significant, this dependent structure can be identified by using an ARMA model, which can be expressed as follows:

$$
\hat{\mathrm{s}}_{\mathrm{t}}=\frac{1-\theta_{1} \mathrm{~B}-\theta_{2} \mathrm{~B}^{2}-\cdots-\theta_{\mathrm{q}} \mathrm{B}^{\mathrm{q}}}{1-\phi_{1} \mathrm{~B}-\phi_{2} \mathrm{~B}^{2}-\cdots-\phi_{\mathrm{r}} \mathrm{B}^{\mathrm{r}}} \mathrm{a}_{\mathrm{t}}, \quad \mathrm{t}=1,2, \ldots, \mathrm{m}
$$

where $\hat{s}_{t}, B$ and $m$ were defined previously; $\theta^{\prime} s$ and $\phi^{\prime} s$ are the parameters of the moving average and the autoregressive components of the model, respectively; $a_{t}$ is a sequence of independent random variables with mean equal to zero and a constant variance. It should be noted that the transformed reference data should be a stationary process since the trend and periodicity components have been removed from the original time series. Stationary in the sense that the mean and the autocorrelation function will not change over time.

The identification of an ARMA model consists of determining the values of $r$ and $q$. The identification is accomplished by using the autocorrelation and partial autocorrelation functions of the stochastic component and a numerical parameters estimation algorithm, as described in several time series textbooks (Box and Jenkins 1976; Brockwell and Davis 2002; Wei, 1990; Pandit and $\mathrm{Wu}$ 1983). Nonlinear regression techniques are used to estimate the parameters of the ARMA model and several statistical programs are available to perform this estimation task, for instance: Statgraphics, Minitab, Matlab, etc. It should be noted that the main purpose of identifying an ARMA model is to remove the autocorrelation structure, as shown in the next step.

\subsection{Step five: computing the ARMA fingerprint}

The ARMA fingerprint is the sequence created by the difference at each point in time between the estimated of stochastic component, $\hat{s}_{t}$, and the estimated stochastic component from the ARMA model, $\tilde{\mathrm{s}}_{\mathrm{t}}$. The ARMA fingerprint can be computed as follows:

$$
\begin{gathered}
\mathrm{f}_{\mathrm{t}}=\widehat{\mathrm{s}}_{\mathrm{t}}-\widetilde{\mathrm{s}}_{\mathrm{t}}, \quad \mathrm{t}=1,2, \ldots, \mathrm{n} \\
\widetilde{\mathrm{s}}_{\mathrm{t}}=\frac{1-\widetilde{\theta}_{1} \mathrm{~B}-\widetilde{\theta}_{2} \mathrm{~B}^{2}-\cdots-\widetilde{\theta}_{\mathrm{q}} \mathrm{B}^{\mathrm{q}}}{1-\widetilde{\phi}_{1} \mathrm{~B}-\widetilde{\phi}_{2} \mathrm{~B}^{2}-\cdots-\widetilde{\phi}_{\mathrm{r}} \mathrm{B}^{\mathrm{r}}} \tilde{\mathrm{a}}_{\mathrm{t}}, \quad \mathrm{t}=1,2, \ldots, \mathrm{m}
\end{gathered}
$$

where $\hat{s}_{t}$ is an estimated of the stochastic component and is computed by using eq. (4); whereas, $\tilde{s}_{t}$ is an estimated of $\hat{s}_{t}$ and is computed by evaluating eq. (9), and $f_{t}$ is the ARMA fingerprint; $\tilde{\mathrm{a}}_{\mathrm{t}}$ are the residuals for the stochastic component; $\tilde{\theta}^{\prime} \mathrm{s}$ and $\widetilde{\phi}^{\prime} \mathrm{s}$ are parameter estimated that must be computed with the $\mathrm{m}$ values of the stochastic component, $\hat{\mathrm{s}}_{\mathrm{t}}$. It should be noted that the model fitting is computed with $\mathrm{t}=1, \ldots, \mathrm{m}$; however, the finger print is computed for the entire time series. 
Thus, if no change has occurred in the underlying process then the fingerprint will behave as a white noise sequence; where a white noise process is a sequence formed by independent random variables with zero mean and constant variance. However, if the process exhibits a significant deviation from the white noise, the ARMA model will show a unique characteristic which will be exhibited either in the mean or in the autocorrelation function of the given sequence and this special sequence will be called here the ARMA fingerprint. Thus, if a significant change occurs in the mean of the process, the ARMA fingerprint will also exhibit a significant deviation from the mean. On the other hand, if a change occurs in the second moment of the process, the fingerprint may also exhibits a significant deviation in the autocorrelation function.

\subsection{Step six: sequential hypothesis testing}

If external forces affected the climate indicator, its ARMA fingerprint will present an autocorrelation function with a significant deviation from the autocorrelation of the white noise process. The suggested procedure will detect changes on the mean, and changes in the autocorrelation function. The exponentially weighted moving average (EWMA) test is adopted to detect the change on the mean of the process at every point in time. EWMA test was proposed by Roberts (1959) and adopted here because it is an efficient test to detect a small shift in the mean and also because it is a robust test in the senses that it is not affected by moderate deviations from the Gaussian process as well as because it is not affected by weak autocorrelated time series. Thus, if a climate change induced a strong autocorrelation function it will be detected by EWMA test. The exponentially weighted average, $\mathrm{z}_{\mathrm{t}}$, of the fingerprint is defined as:

$$
z_{t}=\lambda f_{t}+(1-\lambda) z_{t-1}, \quad t=1, \ldots, n
$$

A significant increment in the mean occurs at time $t$ if $z_{t}>U_{t}$ and a significant decrement occurs in the mean at time $\mathrm{t}$ if $\mathrm{z}_{\mathrm{t}}<\mathrm{L}_{\mathrm{t}}$, where

$$
\begin{array}{ll}
\mathrm{U}_{\mathrm{t}}=\mu+M \sigma \sqrt{\frac{\lambda}{2-\lambda}\left[1-(1-\lambda)^{2 \mathrm{t}}\right]} & \mathrm{t}=1, \ldots, \mathrm{n} \\
\mathrm{L}_{\mathrm{t}}=\mu-M \sigma \sqrt{\frac{\lambda}{2-\lambda}\left[1-(1-\lambda)^{2 \mathrm{t}}\right]} & \mathrm{t}=1, \ldots, \mathrm{n}
\end{array}
$$

where $f_{t}$ is the ARMA fingerprint at time $t, \mu$ and $\sigma$ are the mean and the standard deviation of the ARMA fingerprint sequence during the reference data period $(t=1,2, \ldots, m)$; the initial value of $z_{t}$ can be estimated by the average of the fingerprint during the reference data period; $\lambda$ is a weighted constant and varies between zero to one. $\mathrm{M}$ is a constant that depend on $\lambda$; however, to have better results it is recommended to take the following values of $\lambda=0.2$ and $\mathrm{M}=3$ Montgomery, (2001).

\section{Simulation}

A simulation approach is used to generate a climate indicator to measure the capabilities of the suggested detection test. Mote Carlo simulation technique was used to generate a synthetic time series to represent a climate indicator. It is expected that the climate indicator may be the result of ocean and atmospheric interactions and it may include several patterns 
such as trend, periodicity, and stochastic components. The climate indicator can be represented by the following expression:

$$
x_{t}=\left\{\begin{array}{lr}
T_{t}+P_{t}+s_{t}, & t=1, \ldots, m \\
T_{t}+P_{t}+s_{t}+\psi_{t} & t=m+1, m+2, \ldots, n
\end{array}\right.
$$

where

$$
\begin{gathered}
\mathrm{T}_{\mathrm{t}}=5+0.05 \mathrm{t}+0.0004 \mathrm{t}^{2} \\
\mathrm{P}_{\mathrm{t}}=8 \cos \left(\frac{2 \pi \mathrm{t}}{12}\right)+\left(4+\frac{\ln (\mathrm{t}+1)}{16}\right) \cos \left(\frac{2 \pi}{30} \mathrm{t}\left(1+\frac{\ln (\mathrm{t}+1}{100}\right)\right) \\
\mathrm{s}_{\mathrm{t}}=0.2 \mathrm{~s}_{\mathrm{t}-1}+0.6 \mathrm{~s}_{\mathrm{t}-2}-0.5 \mathrm{a}_{\mathrm{t}-1}+\mathrm{a}_{\mathrm{t}} \\
\Psi_{\mathrm{t}}= \begin{cases}3 \sigma, & \mathrm{t}>m \\
0, & \text { otherwise }\end{cases} \\
\Psi_{\mathrm{t}}= \begin{cases}0.1 \mathrm{t} & \mathrm{t}>m \\
0, & \text { otherwise }\end{cases}
\end{gathered}
$$

The variable $x_{t}$ is the climate indicator at time $t$; the variable $T_{t}$ is a quadratic trend; $P_{t}$ is a periodic component and is composed by two functions, the first function includes a large amplitude with period equal to twelve, and the second function has a moderated amplitude with a function of time and a fixe period equal to 30; the stochastic component is an $\operatorname{ARMA}(2,1)$ process, $a_{t}$ is a Gaussian noise sequence with zero mean and variance 9. A similar function was also used by Nicolay (2010) to represents a climate indicator. The variable $\psi_{\mathrm{t}}$ represents the induced climate change, which may have a step (17a) or a ramp function $(17 b)$ that starts when $t=m+1$. The step function represents a sudden increment of a meteorological variable whereas the ramp function is a slow and persistent increment of climate change. It is assumed that the step change occurred at time $\mathrm{m}+1$ and will persist up to the end of the series with a magnitude of 3 times the standard deviation of the white noise, $\sigma$. When the ramp function is used the persistent climate change will be very small at the beginning of the change and the simulated climate change will become evident after the time approaches to $\mathrm{n}$. It is expected that the climate change will be detected right after the change has occurred for the case of the step function; however, when the ramp function is simulated the change is detected after some delay (about 35 units of time).

Figure 1 shows the different components of the simulated time series. The top panel on the right of Figure 1 shows the simulated trend and the top panel on the left shows the periodic function. The middle panel on the left of Figure 1 shows the stochastic component whereas the middle panel on the right shows the step function. The bottom panel of Figure 1 shows the simulated climate indicator, which is the sum of the previously plotted variables.

As described in the previous section, the procedure to implement the detection test includes six steps. The first step consists on selecting a climate indicator to be studied and in this case, the simulated climate indicator $\mathrm{x}_{\mathrm{t}}$, is the selected time series.

The second step consists on dividing the time series in two sets, the first set includes one hundred values, which were assigned to the reference data; i.e., $\mathrm{m}=100$, and the remaining observations correspond the testing data.

The third step consists on identifying the deterministic components, which includes the trend and the periodic component. Figure 2 shows the sample autocorrelation function of 
the simulated reference data, $\mathrm{x}_{\mathrm{t}}$. This autocorrelation function indicates that the underlying time series is not stationary and includes a strong periodic component. Thus, it is necessary to remove first the trend component to properly identify the periodic functions, and finally, remove the periodic component to develop a stationary time series.
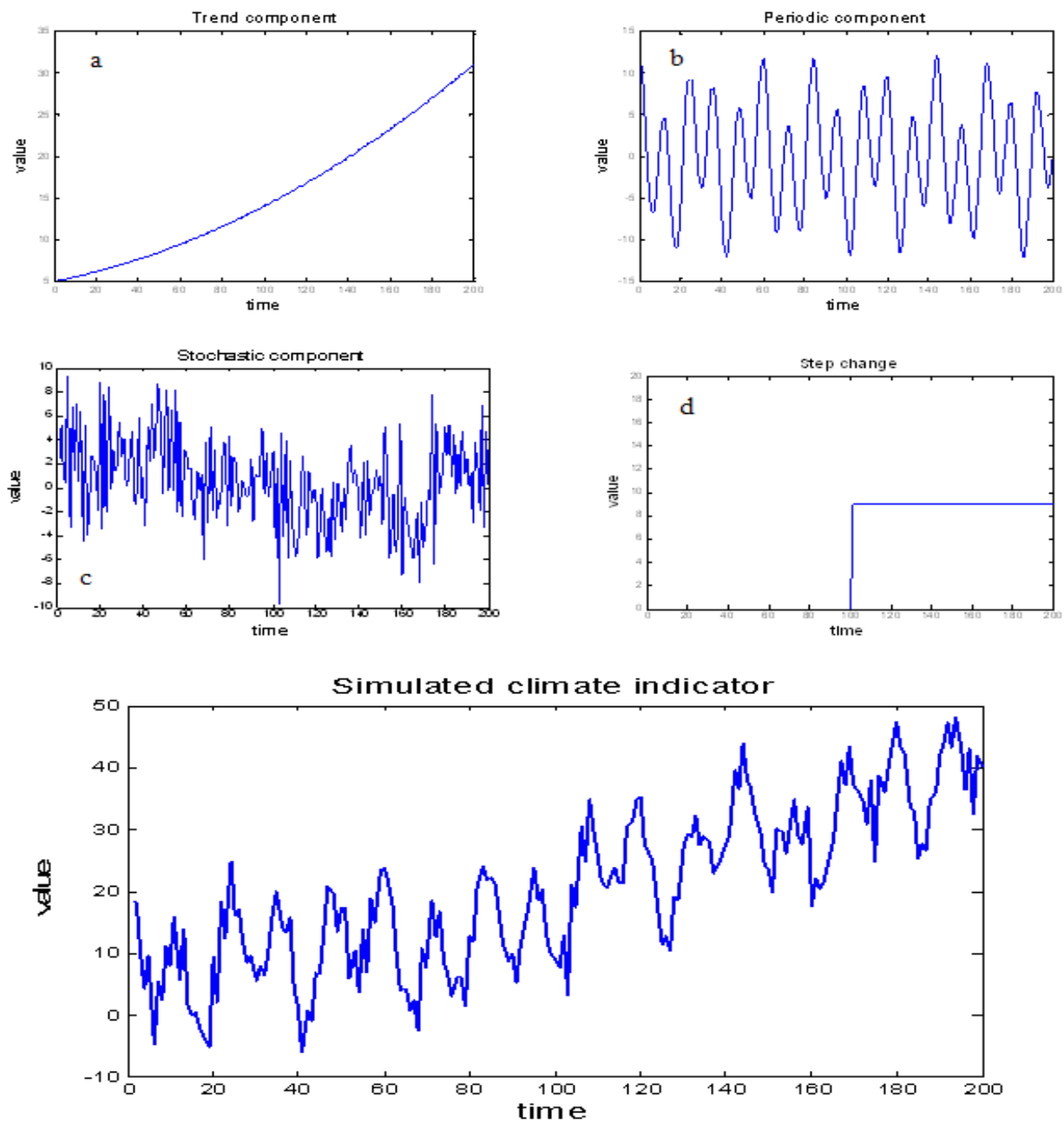

Fig. 1. Panels $a, b, c$ and $d$ show the trend component, the periodic component, the stochastic component, and the step change, respectively. Panel at the bottom shows the climate indicator, which is the result of the sum of the described components.

A quadratic model was used to estimate the trend of the climate indicator. Thus, the following regression model was identified:

$$
\widehat{\mathrm{T}}_{\mathrm{t}}=7.5+0.041 \mathrm{t}+0.0003 \mathrm{t}^{2}, \quad \mathrm{t}=1, \ldots, 100
$$


Statistical analysis shows that the included parameters are significant at 5\% level. The simulated reference data and the estimated trend are given on Figure 3. In this figure, the continuous and smooth line shows the estimated trend and the broken and continues line is the simulated reference data.

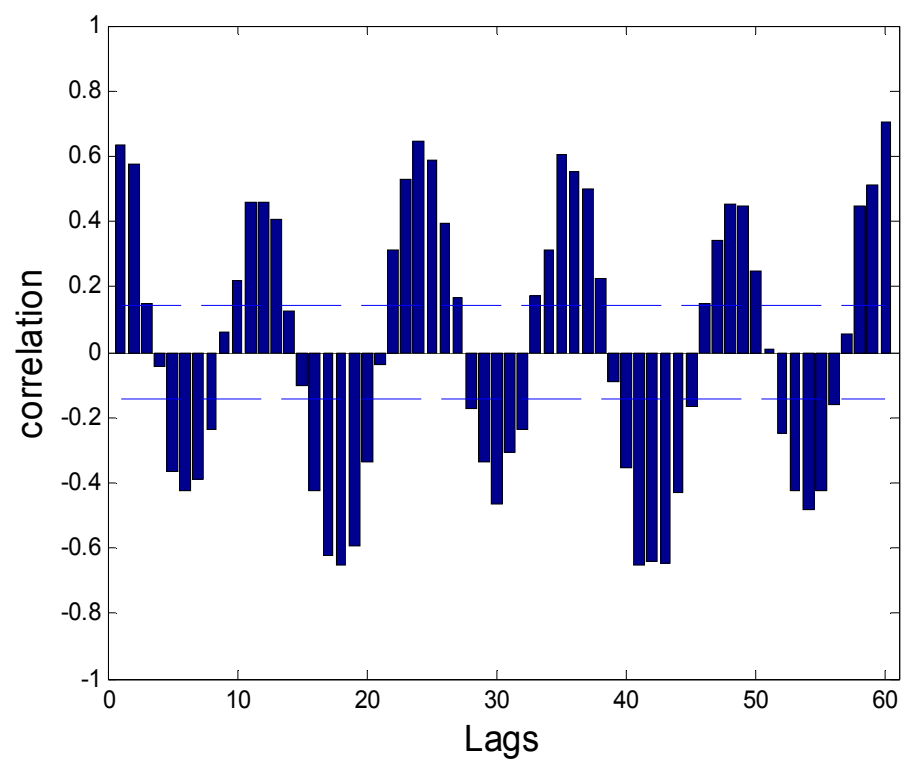

Fig. 2. Autocorrelation function of the simulated reference data.

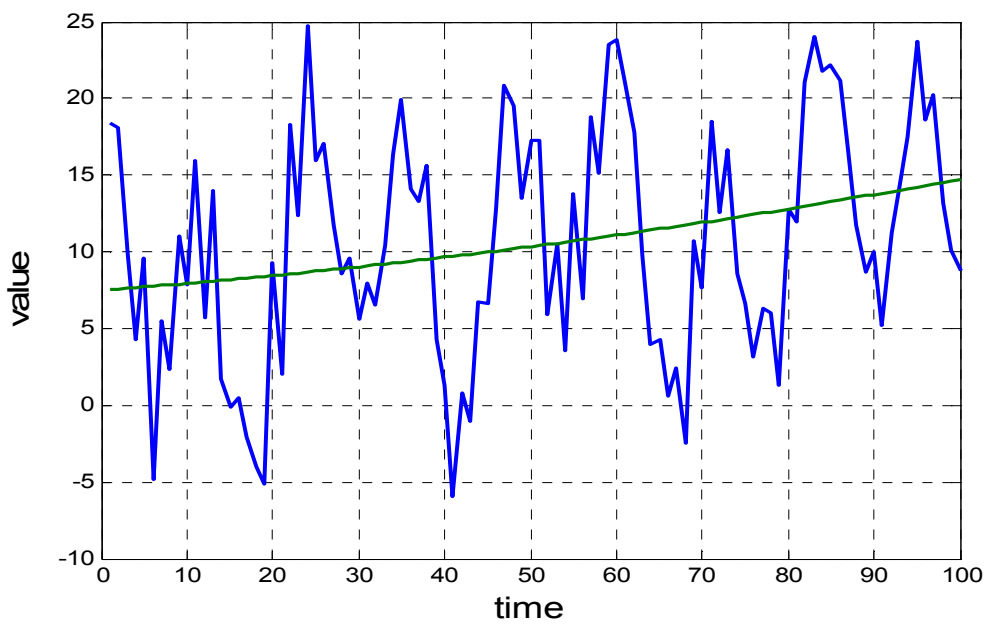

Fig. 3. Simulated reference data and estimated trend. 
The trend was removed from the entire time series to create the detrended sequence, which is given below:

$$
\mathrm{y}_{\mathrm{t}}=\mathrm{x}_{\mathrm{t}}-\widehat{\mathrm{T}}_{\mathrm{t}}, \mathrm{t}=1, \ldots, 200
$$

The Fast Fourier Transform was used to develop the periodorgram and two significant ordinates were found indicating that the periodic component includes two harmonic functions, as exhibits in Figure 4. The estimated periods of these functions are 11.9 and 28.4.

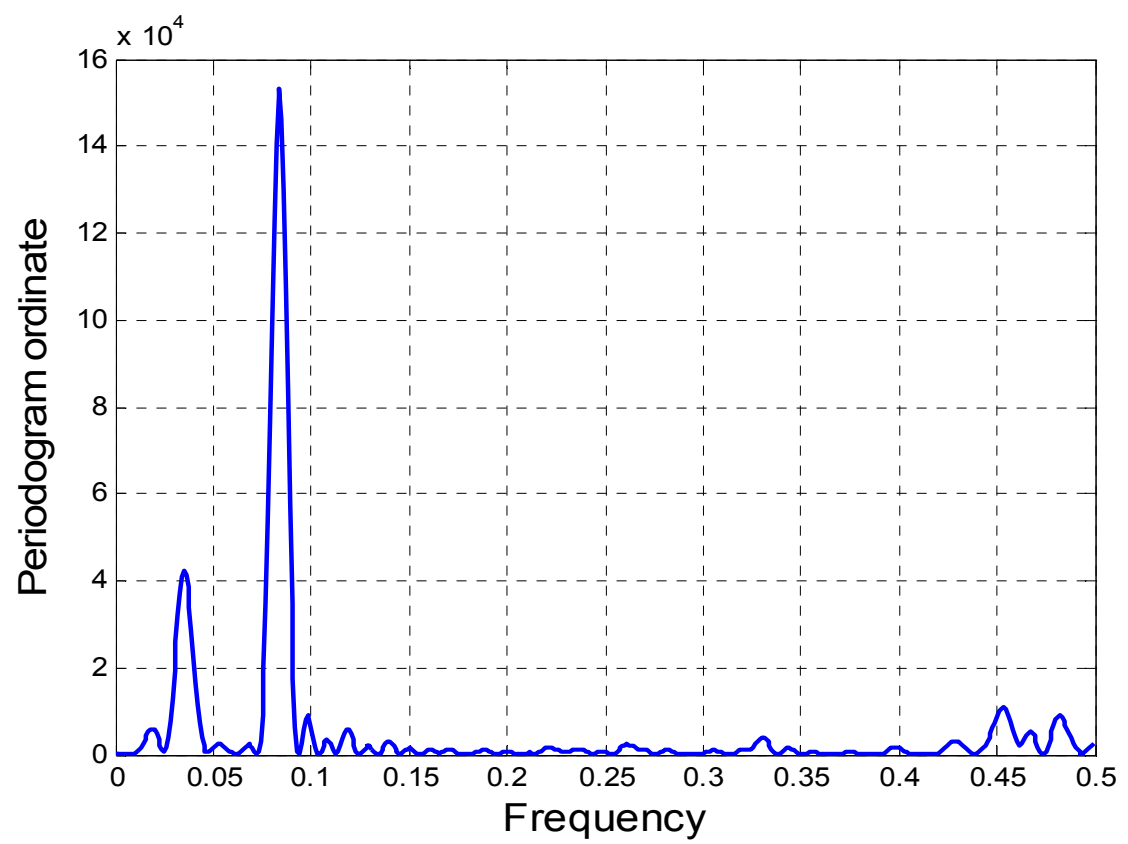

Fig. 4. The periodogram of the deterended time series shows that there are two significant harmonics with the largest ordinates at the frequencies of 0.084 and 0.035 that correspond to the period of 11.9 and 28.4, respectively.

Periodogram and autocorrelation function show that the detrended reference data has a periodic component that can be modeled by using the following sinusoidal function:

$$
\widehat{\mathrm{P}}_{\mathrm{t}}=0.0098-0.5705 \sin \left(\frac{2 \pi \mathrm{t}}{11.9}\right)+8.1084 \cos \left(\frac{2 \pi \mathrm{t}}{11.9}\right)-0.9133 \sin \left(\frac{2 \pi \mathrm{t}}{28.4}\right)+4.3805 \cos \left(\frac{2 \pi \mathrm{t}}{28.4}\right)
$$

Figure 5 shows the reference data with the estimated periodic component. The sinusoidal continuous line shows the estimated periodic component while the broken and continuous line shows the stochastic data.

The trend and the periodic components are removed from the simulated reference data to compute the stochastic component as follows:

$$
\widehat{s}_{\mathrm{t}}=\mathrm{x}_{\mathrm{t}}-\widehat{\mathrm{T}}_{\mathrm{t}}-\widehat{\mathrm{P}}_{\mathrm{t}}
$$




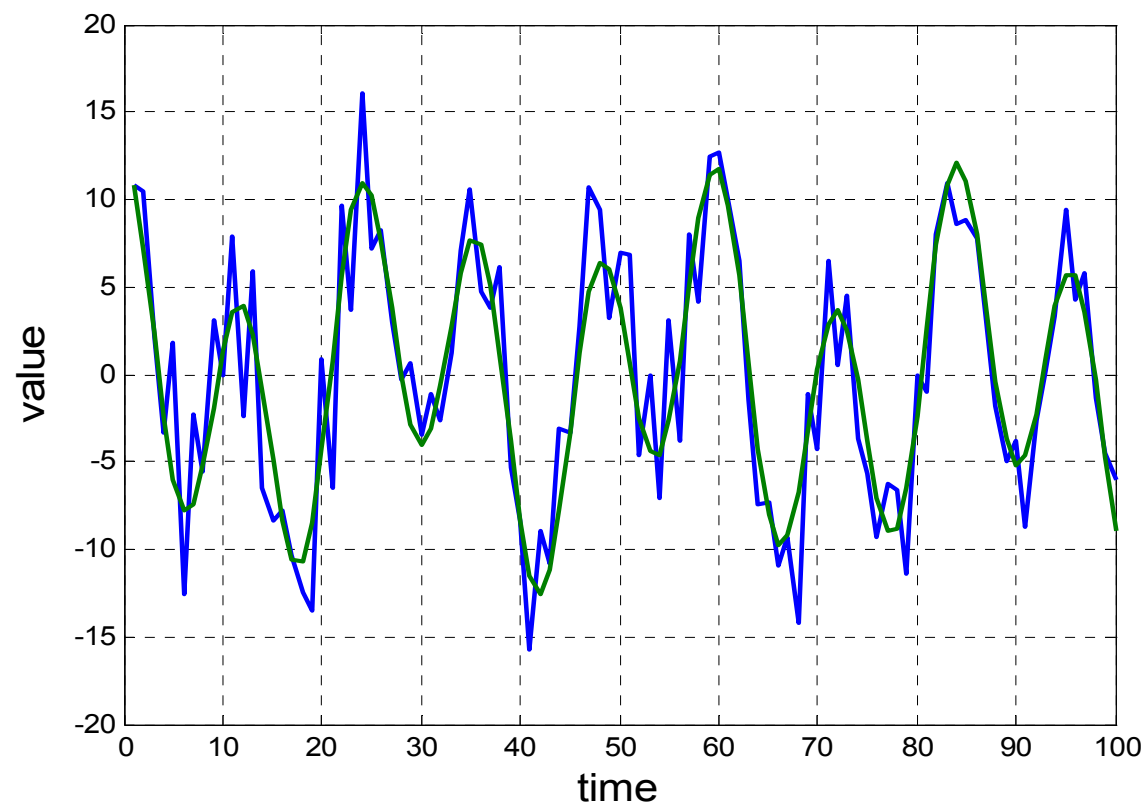

Fig. 5. This figure shows the reference data after removing the trend component and the estimated periodic component. The smooth and continuous line shows the estimated periodic component.

The fourth step consists on identifying a time series model for the stochastic component. The sample autocorrelation function and a parameter estimation algorithm are used simultaneously to identify the corresponding ARMA model. It can be shown that the theoretical autocorrelation function for and $\operatorname{ARMA}(2,1)$ can be written as follows (RamirezBeltran and Sastri 1997):

$$
\rho_{\mathrm{k}}=\frac{\gamma_{\mathrm{k}}}{\gamma_{0}}
$$

where

$$
\begin{gathered}
{\left[\begin{array}{l}
\gamma_{0} \\
\gamma_{1} \\
\gamma_{2}
\end{array}\right]=\left[\begin{array}{ccc}
1 & -\phi_{1} & -\phi_{2} \\
-\phi_{1} & 1-\phi_{2} & 0 \\
-\phi_{2} & -\phi_{1} & 1
\end{array}\right]^{-1}\left[\begin{array}{c}
1+\theta\left(\phi_{1}+\theta\right) \\
\theta \\
0
\end{array}\right] \sigma^{2}} \\
\gamma_{\mathrm{k}}=\phi_{1} \gamma_{\mathrm{k}-1}+\phi_{2} \gamma_{\mathrm{k}-2}, \quad \mathrm{k} \geq 3
\end{gathered}
$$

where $\rho_{\mathrm{k}}$ and $\gamma_{\mathrm{k}}$ are the autocorrelation and autocovariance functions at lag $\mathrm{k}$ of the stochastic component, respectively; $\phi^{\prime}$ s are the autoregressive parameters, and $\theta$ is the moving average parameter, and $\sigma^{2}$ is the variance of the white noise. The simulation was based on the following values: $\phi_{1}=0.2, \phi_{2}=0.6, \theta=-0.5$ and $\sigma=3$.

The left panel of Figure 6 shows the theoretical autocorrelation function of and $\operatorname{ARMA}(2,1)$ model, and the right panel of Figure 6 shows the sample autocorrelation function of $\hat{s}_{t}$. 
The Matlab computer software (MathWorks, 2000) was used to estimate the parameters of the $\operatorname{ARMA}(2,1)$, and the estimated model can be written as follows:

$$
\tilde{s}_{\mathrm{t}}=0.19 \tilde{\mathrm{s}}_{\mathrm{t}-1}+0.56 \tilde{\mathrm{s}}_{\mathrm{t}-2}-0.68 \tilde{\mathrm{a}}_{\mathrm{t}-1}, \quad \mathrm{t}=1, \ldots, 100
$$

Data also provide information to estimate the standard deviation of the noise, which is $\widetilde{\sigma}=2.74$.
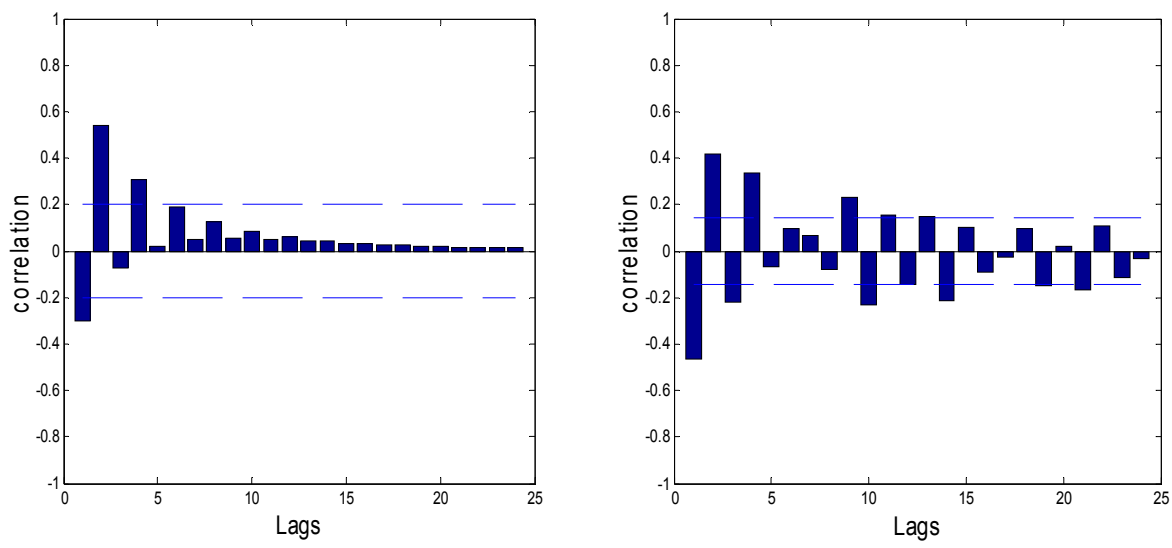

Fig. 6. Theoretical (left) and sample (right) autocorrelation functions for the stochastic component.

The fifth step consists of deriving the ARMA fingerprint. The estimated parameters in the previous step are used to compute the stochastic time series and removed the autocorrelation structure from the simulated stochastic component. Thus, the ARMA fingerprint was computed as follows:

$$
\mathrm{f}_{\mathrm{t}}=\hat{\mathrm{s}}_{\mathrm{t}}-\tilde{\mathrm{s}}_{\mathrm{t}}, \quad \mathrm{t}=1, \ldots, 200
$$

Figure 7 shows the ARMA fingerprint, and the first one hundred values resembles to the pattern of a white noise process. However, the last part of the fingerprint shows a significant deviation from the white noise.

The sixth step consists on applying the sequential hypothesis test for detecting the induced climate change. Essentially, the EWMA test includes a 95\% confidence interval for the mean of a white noise process. Thus, the values that are outside of the interval indicate that a significant deviation has occurred on the mean; and consequently, that particular observation shows the time when the climate change becomes evident. The left panel of Figure 8 shows that the induced climate change was detected at time $t=102$, and the red stats that fall beyond the 95 confidence interval indicate that the climate change is evident during this period of time. In this particular exercise, the size of the step change was three time the standard deviation of the noise $(3 \sigma=9)$. A climate change was also simulated by using the ramp function. Thus, the equation $(17 \mathrm{~b})$ was used to induce a slowly increasing climate change. The right panel of Figure 8 shows the results for the ramp function, which indicates that after 35 time units the change becomes evident. The right panel of Figure 8 also shows 
the sequential hypothesis test, which indicates the climate change is large enough to be detected, and the detection occurs at time $t=135$.

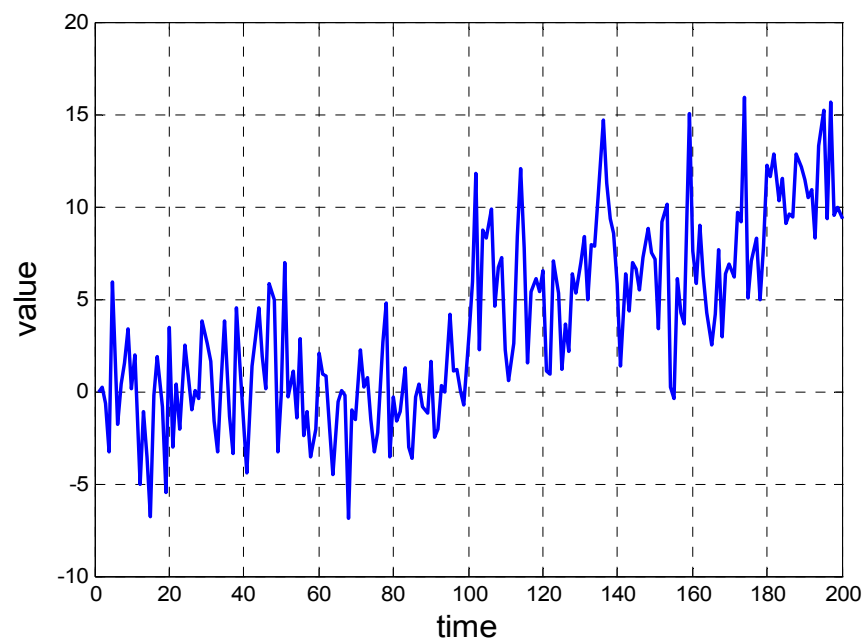

Fig. 7. The ARMA fingerprint of the simulated process.
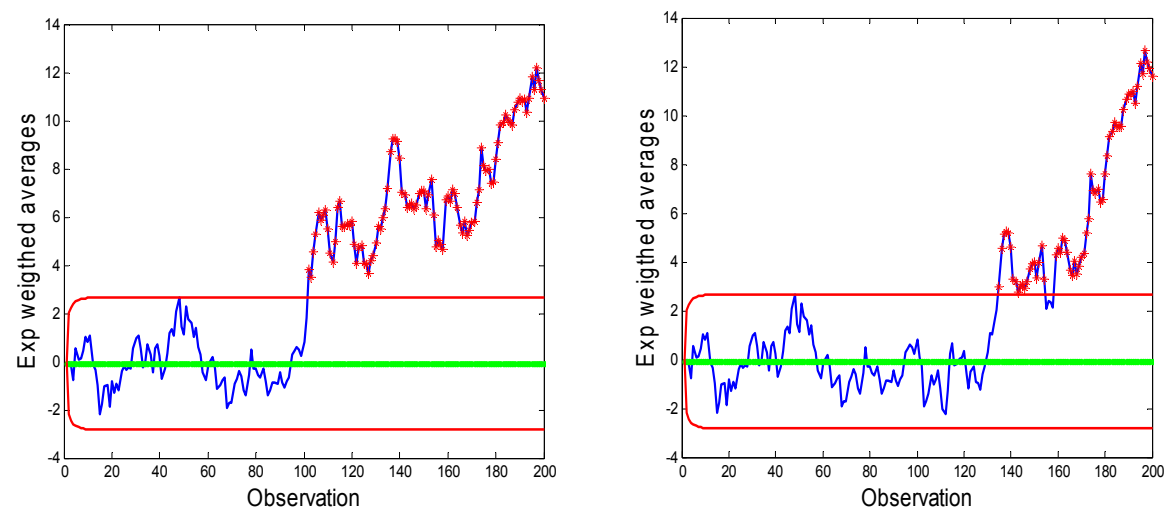

Fig. 8. The left panel shows the performance of the detection test when a step change has been induced and this change has been detected at $t=102$. On the other hand, the right panel shows results when the climate change was induced by a ramp function. In this case the change was detected at $\mathrm{t}=135$; i.e., after 35 units of delay.

\section{Climate change detection}

Four data sets were used to implement the climate change detection test. The first two sets are associated with the factors that induced a climate change, and other two are climate indicators related to meteorological variables that exhibited the vestiges of a climate change embedded along the time series. 


\subsection{Attribution variables}

The factors that induced a climate change are known as attribution variables and in this study, we selected two attribution variables (IPCC, 2001). The sunspots are considered as a natural attribution variable; i.e., the induced changes are the result of sun energy variations that directly impact the Earth climate conditions, whereas the carbon dioxide $\left(\mathrm{CO}_{2}\right)$ emissions are considered as an anthropogenic attribution variable.

\subsubsection{Sunspots}

Sun exhibits signs of varying activity in the form sunspots. These are dark areas, which are seen at lower latitudes and crossing the phase of the sun as it rotates, and are cooler than the surrounding chromospheres. A sunspot consist of two regions a dark central umbra at temperature of around $4,000^{\circ} \mathrm{K}$ and surrounding lighter penumbra at around $5,000^{\circ} \mathrm{K}$. Thus, the darkness is purely a matter of contrast that appears dark compared to the general brightness of the sun. A spot may be from $1 \times 10^{3}$ to $2 \times 10^{5} \mathrm{~km}$ in diameter with a life cycle from hours to months (Burroughs, 2001). If the amount of energy emitted by the sun varies over the time and the Earth is receiving a radiation from the sun; consequently, some changes on the Earth surface temperature may be attributed to variation of solar radiation. In 1843 Heinrich Schwabe (Burroughs, 2001) discovered that the number of sun spots exhibits a periodically behaviour; however, it was until 1980 when satellite data confirmed such discovery. She et al. (2004) pointed out that there is a relationship between temperatures observed in mesopause and the effect of solar cycle. Satellite data has been used as a medium to support that an indirect measurement of solar radiation can be obtained by studying the behaviour of sunspots. For instance, Julca (2007) shows that sunspots and observed solar irradiances exhibit 0.77 of correlation coefficient and this result confirms that the solar activity may be studied by analysing the behaviour of sunspots. Figure 9 exhibits the comparison of observed sunspot pattern and solar irradiance during the period 1979-2005. The analysed time series of sunspots was obtained from the Royal Observatory of Belgium (http://sidc.oma.be/sunspot-data/), and the studied period was from January 1750 until February 2011. Figure 10 shows the patterns of the sunspots over the studied period.

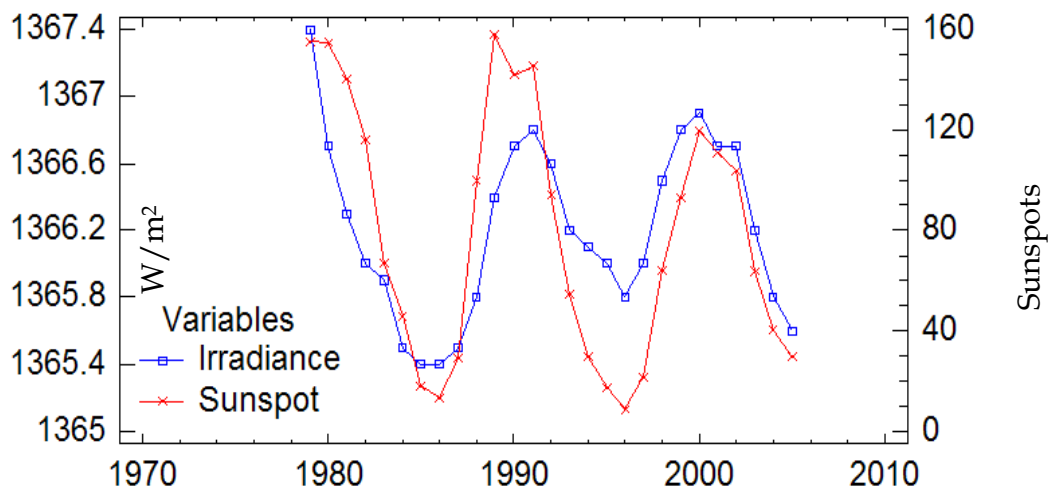

Fig. 9. Sunspots and solar radiation. The left vertical axis shows the scale of solar radiation and is given in $\mathrm{W} / \mathrm{m}^{2}$; whereas, the right scale shows the number of sunspots. 


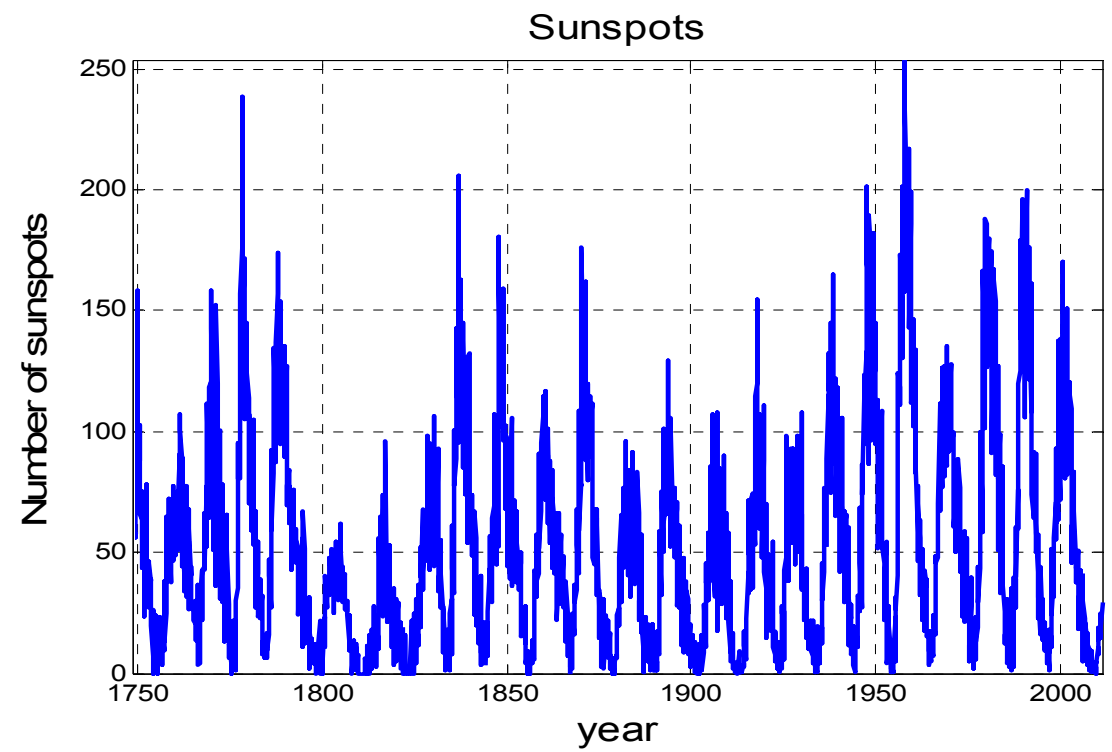

Fig. 10. The monthly sunspots form January 1749 to February 2011.

The algorithm for detecting climate change was applied to identify whether or not the sunspots attribution variable exhibits a significant change on the mean. The half of the available observations was used as the reference data (from January 1749 to December 1880) and the remaining part of the series was used as the testing data (from January 1881 to February 2011). The selected reference data do not exhibit a significant trend; and consequently, no trend was removed. However, sunspots show an unstable variance; i.e., a data transformation should be explored to stabilize the variance. Logarithmic transformation was discarded since it produces extreme lower values and a significant bias is introduced to the data. The squared root transformation was applied to data and better results were found. Six harmonic functions were needed to model the periodic component. Table 1 shows the parameter estimation of the sinusoidal functions. After removing the periodic component, an ARMA $(2,1)$ model was identified into the stochastic component. Thus, the fingerprint of sunspots was computed as follows:

$$
f_{t}=\hat{s}_{t}-\tilde{s}_{t}
$$

where

$$
\begin{gathered}
\hat{\mathrm{s}}_{\mathrm{t}}=\sqrt{\mathrm{x}_{\mathrm{t}}}-\widehat{\mathrm{P}}_{\mathrm{t}} \\
\widehat{\mathrm{P}}_{\mathrm{t}}=-0.201+\sum_{\mathrm{i}=1}^{6} \widehat{\mathrm{b}}_{\mathrm{i}} \sin \left(\frac{2 \pi \mathrm{t}}{\mathrm{p}_{\mathrm{i}}}\right)+\widehat{\mathrm{c}}_{\mathrm{i}} \cos \left(\frac{2 \pi \mathrm{t}}{\mathrm{p}_{\mathrm{i}}}\right) \\
\tilde{\mathrm{s}}_{\mathrm{t}}=\left(\frac{1-0.7057 \mathrm{~B}}{1-1.164 \mathrm{~B}-0.1903 \mathrm{~B}^{2}}\right) \tilde{\mathrm{a}}_{\mathrm{t}}
\end{gathered}
$$

where $f_{t}$ is the ARMA fingerprint and $x_{t}$ is the number of sunspots at the month $t(t=$ $1, \ldots, n), n=3146$, and $m=1573$; the standard deviation of the estimated white noise 
process is 1.099. After removing the seasonal component the ARMA fingerprint technique was implemented and the monthly stochastic component shows a significant increment during about three decades from 1955 to 1989 and especially during the first decade (19551965) it was detected a significant increment of sunspots as shown in Figure 11.

\begin{tabular}{|c|c|c|c|}
\hline $\mathrm{i}$ & $\hat{\mathrm{b}}_{\mathrm{i}}$ & $\hat{\mathrm{c}}_{\mathrm{i}}$ & $\mathrm{p}_{\mathrm{i}}$ (months) \\
\hline 1 & -0.6842 & 1.8636 & 135 \\
\hline 2 & 1.3737 & -1.1725 & 899 \\
\hline 3 & -0.1579 & 1.2634 & 121 \\
\hline 4 & 0.19 & 1.2516 & 166 \\
\hline 5 & -0.4951 & -0.9182 & 101 \\
\hline 6 & 0.4223 & -0.3006 & 111 \\
\hline
\end{tabular}

Table 1. Parameter estimation of the sinusoidal function

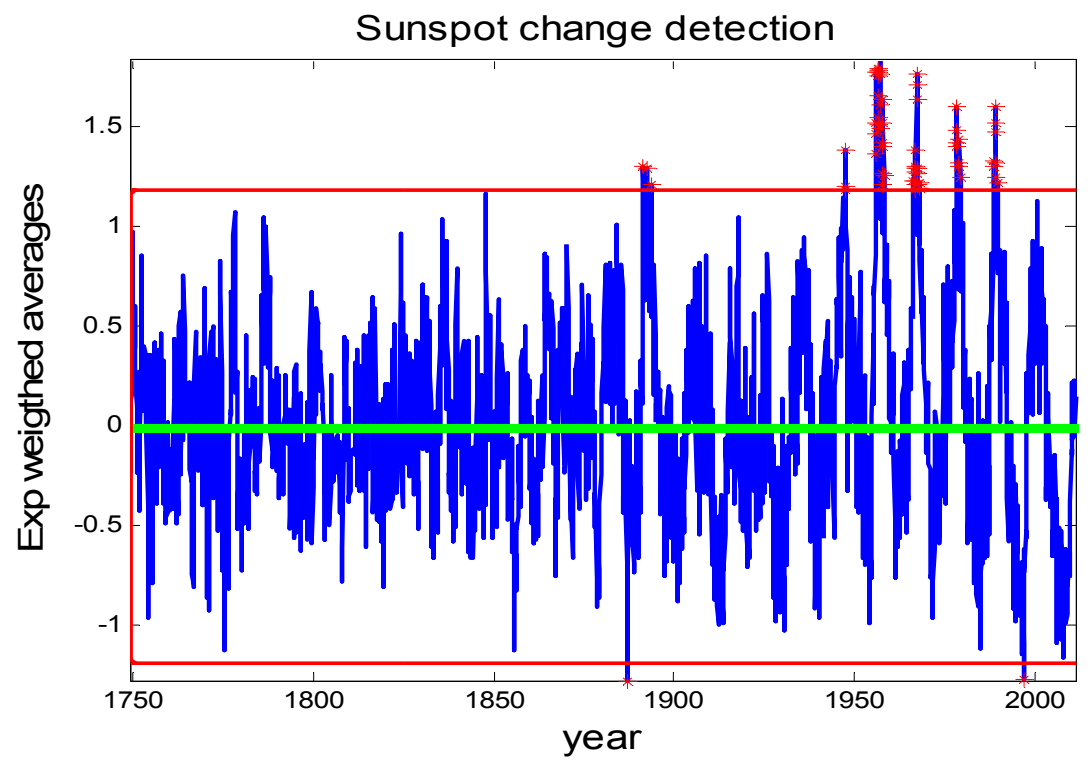

Fig. 11. Sunspots show an evident increasing amount of sunspots from 1955 to 1989, with a significant increment during the decade (1955 to 1965). The reference data were from January 1749 to December 1880, and the testing data from January 1881 to February 2011.

The direct link between sunspot number and solar output fits with the hypothesis that cold period known as the Little Ice Age and the colder weather of the late seventeen century was the result of an almost complete absence of sunspots known as the Maunder minimum (Burroughs, 2001). The climate impact of changes in solar radiance in the ultraviolet (UV) region has been suggested. Because wavelengths between 200 to $300 \mathrm{~nm}$ are absorbed high in the stratosphere by oxygen and ozone, they initiate photochemical reactions which influence the weather at lower levels. It has been shown that the amount of solar radiation entering the lower atmosphere varies with solar activity, as a result of alterations in 
stratospheric ozone concentrations caused by the changing UV flux. This reduces the amount of solar energy reaching the lower atmosphere in middle and high latitudes in winter when solar activity is high. These changes could have a significant impact on global circulation; the increase solar UV radiance in the lower tropical stratosphere will expand the Hadley circulation leading to a pole ward shift of the sub-tropical westerly jet (Burroughs, 2001). Another consequence of changing UV fluxes reaching the lower atmosphere is to affect the formation of free-radicals in the lower atmosphere (hydroxyl radical). This alters the production of condensation nuclei and hence the formation of clouds. In effect, more UV radiation reaching the troposphere will increase the concentration of condensation nuclei and hence make it cloudier environment. Thus, varying of solar activity it will modify the climate over the Earth.

\subsubsection{Carbon dioxide}

The carbon dioxide time series was obtained from Mauna Loa station Hawaii. Data are reported as a dry air mole fraction defined as the number of molecules of carbon dioxide divided by the number of all molecules in air, including carbon dioxide $\left(\mathrm{CO}_{2}\right)$ itself, after water vapor has been removed. Thus, a mole fraction of $\mathrm{CO}_{2}$ is expressed as parts per million (ppm) and is the number of molecules of $\mathrm{CO}_{2}$ in every one million molecules of dried air. The $\mathrm{CO}_{2}$ monthly data is the monthly mean $\mathrm{CO}_{2}$ mole fraction determined from daily averages. This data set includes about 53 years of data from March 1958 to February 2011. The underlying data includes a few missing values which were estimated by the data source (http://www.esrl.noaa.gov/gmd/ccgg/trends/). Information from this station has the longest continuous record of $\mathrm{CO}_{2}$ concentrations in the world. This climate attribution variable has been considered as one of the most favourable locations for measuring undisturbed air because of the Hawaii environmental conditions. It should be noted that the volcanic events were excluded from the records (Keeling and Whorf 2005). Figure 12 shows the behaviour of the observed $\mathrm{CO}_{2}$.

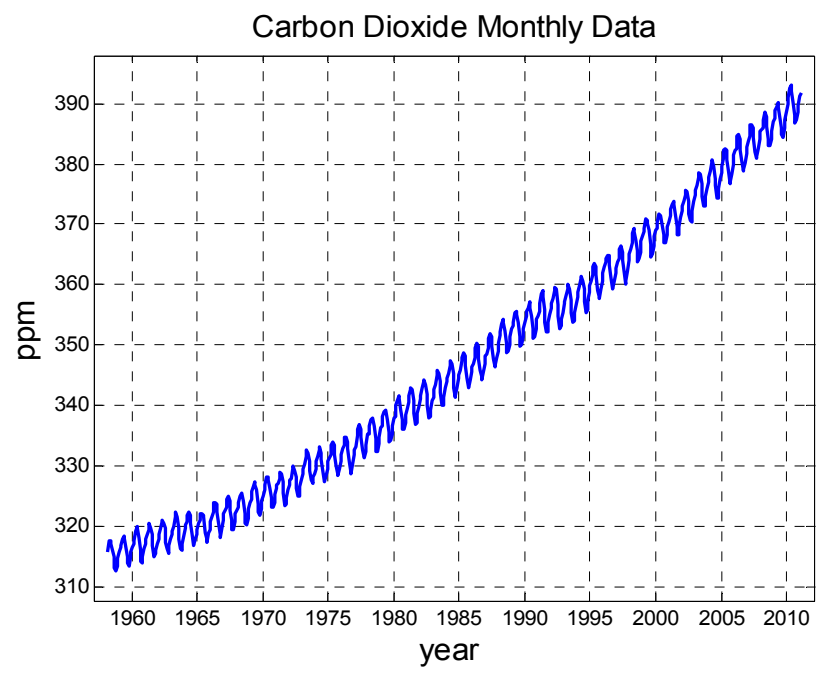

Fig. 12. Monthly carbon dioxide at Mauna Loa Hawaii, from March 1958 to February 2011. 
The carbon dioxide shows a strong trend and seasonality components. The reference data includes 312 monthly values and correspond to the period of 26 years from March 1958 to February 1984 and the testing data includes 27 years of data from March 1984 to February 2011. To perform a climate change detection analysis there may be two possibilities, depending of the identified trend. It can be fitted either a linear or a quadratic trend to the reference data, and the parameters of both the linear and the quadratic trend are significant and also the proportions of explained variance are about the same; therefore, it is justifiable the application of a linear or a quadratic trend. However, the results are quite different and the interested reader should be aware about the interpretation of results.

The analyses of linear and quadratic trend are given in Table 2. The first column indicates the component to be analysed and the second and the third columns refer to results from the linear and the quadratic analysis, respectively.

\begin{tabular}{|c|c|c|c|c|c|c|c|c|}
\hline Component & \multicolumn{4}{|c|}{ Linear Trend } & \multicolumn{4}{|c|}{ Quadratic Trend } \\
\hline Fingerprint & \multicolumn{4}{|c|}{$\mathrm{f}_{\mathrm{t}}=\hat{\mathrm{s}}_{\mathrm{t}}-\tilde{s}_{\mathrm{t}}$} & \multicolumn{4}{|c|}{$\mathrm{f}_{\mathrm{t}}=\hat{\mathrm{s}}_{\mathrm{t}}-\tilde{\mathrm{s}}_{\mathrm{t}}$} \\
\hline Stochastic & \multicolumn{4}{|c|}{$\widehat{s}_{t}=x_{t}-\widehat{T}_{t}-\widehat{P}_{t}$} & \multicolumn{4}{|c|}{$\hat{\mathrm{S}}_{\mathrm{t}}=\mathrm{x}_{\mathrm{t}}-\widehat{\mathrm{T}}_{\mathrm{t}}-\widehat{\mathrm{P}}_{\mathrm{t}}$} \\
\hline Trend & \multicolumn{4}{|c|}{$\widehat{\mathrm{T}}_{\mathrm{t}}=312.95+0.0918 \mathrm{t}$} & \multicolumn{4}{|c|}{$\widehat{T}_{t}=315.34+0.0461 t+0.000145 t^{2}$} \\
\hline \multirow{4}{*}{$\begin{array}{l}\text { Periodic } \\
\text { component }\end{array}$} & \multicolumn{4}{|c|}{$\widehat{\mathrm{P}}_{\mathrm{t}}=\sum_{\mathrm{i}=1} \widehat{\mathrm{b}}_{\mathrm{i}} \sin \left(\frac{2 \pi \mathrm{t}}{\mathrm{p}_{\mathrm{i}}}\right)+\widehat{\mathrm{c}}_{\mathrm{i}} \cos \left(\frac{2 \pi \mathrm{t}}{\mathrm{p}_{\mathrm{i}}}\right)$} & \multicolumn{4}{|c|}{$\widehat{\mathrm{P}}_{\mathrm{t}}=\sum_{\mathrm{i}=1} \hat{\mathrm{b}}_{\mathrm{i}} \sin \left(\frac{2 \pi \mathrm{t}}{\mathrm{p}_{\mathrm{i}}}\right)+\widehat{\mathrm{c}}_{\mathrm{i}} \cos \left(\frac{2 \pi \mathrm{t}}{\mathrm{p}_{\mathrm{i}}}\right)$} \\
\hline & $\mathrm{i}$ & $\hat{b}_{i}$ & $\widehat{c}_{i}$ & $\begin{array}{c}\mathrm{p}_{\mathrm{i}} \\
\text { (months) }\end{array}$ & i & $\hat{b}_{\mathrm{i}}$ & $\hat{\mathrm{c}}_{\mathrm{i}}$ & $\begin{array}{c}\mathrm{p}_{\mathrm{i}} \\
\text { (months) }\end{array}$ \\
\hline & 1 & 2.5017 & 0.971 & 12 & 1 & 2.5011 & 0.969 & 12 \\
\hline & 2 & -0.6331 & -0.3541 & 6 & 2 & -0.6334 & -0.3545 & 6 \\
\hline Stochastic & \multicolumn{4}{|c|}{$\left(\frac{1-0.5882 \mathrm{~B}}{1-1.235 \mathrm{~B}-0.2431 \mathrm{~B}^{2}}\right) \tilde{\mathrm{a}}_{\mathrm{t}}$} & \multicolumn{4}{|c|}{$\left.\frac{1-0.6327 \mathrm{~B}}{-1.217 \mathrm{~B}+0.2723 \mathrm{~B}^{2}}\right) \tilde{\mathrm{a}}_{\mathrm{t}}$} \\
\hline $\begin{array}{c}\text { Standard } \\
\text { deviation of } \\
\tilde{\mathrm{a}}_{\mathrm{t}} \\
\end{array}$ & \multicolumn{4}{|c|}{0.3146} & \multicolumn{4}{|c|}{0.3036} \\
\hline
\end{tabular}

Table 2. Analysis for a linear and a quadratic trend.

The left panel of Figure 13 shows the linear trend that was fitted to the reference data and this function was evaluated for $t$ during the testing period $(t=313,314, \ldots, 636)$. This figure indicates that the expected mean (straight line) is smaller than the actual mean during the testing period. Therefore, the detection test should indicate that there is a significant increment on the mean during the testing data. This figure indicates that during the reference data the mean of $\mathrm{CO}_{2}$ has an increasing rate of 0.0918 ppm per month; however, during the testing period the increasing rate growth larger than the linear trend, since the sequential test detects an increment with respect to the mean (linear trend). On the other hand, the right panel of Figure 13 shows a quadratic trend that was fitted to the reference data and this function was evaluated for $t$ during the testing period. This figure indicates that the expected mean (parabola) is larger than the actual mean during the testing period. Therefore, the detection test should indicate that there is a reduction with respect to the mean (quadratic trend). Apparently, the emissions of $\mathrm{CO}_{2}$ during the last decade have been reduced with respect to the quadratic emission rate. However, the reduction on emission is still larger than the linear trend. 

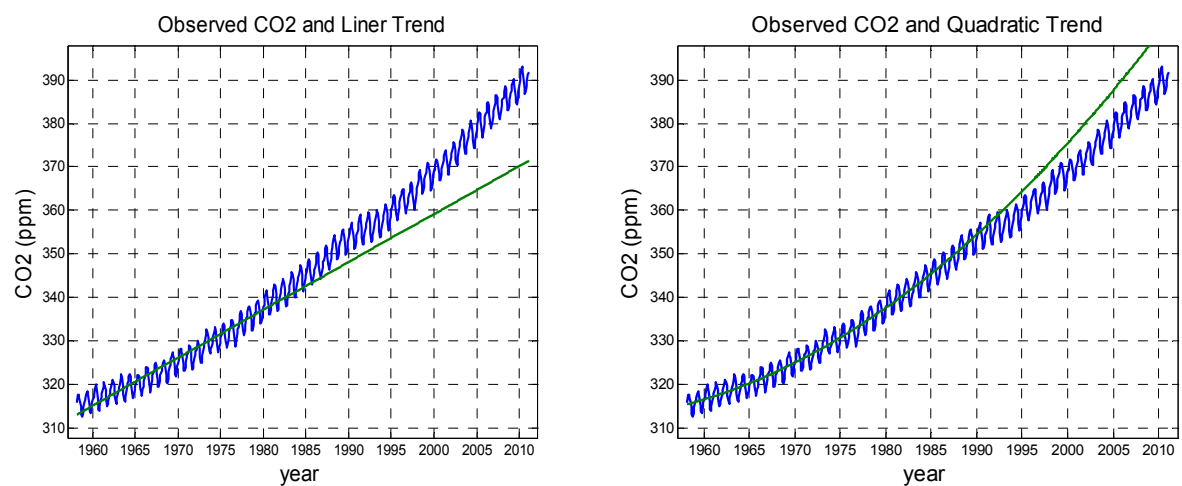

Fig. 13. The left panel shows the observed $\mathrm{CO}_{2}$ and a linear trend, which was fitted to the reference data and evaluated during the testing data. The right panel shows the observed $\mathrm{CO}_{2}$ and the quadratic trend, which was fitted to the reference data and evaluated during the testing data. The reference data is from March 1958 to February 1984 and the testing data is from March 1984 to February 2011.

The left panel of Figure 14 shows that in 1988, the emission rate of $\mathrm{CO}_{2}$ is larger than the mean rate 0.0918 ppm per month and this event becomes evident during the period of 19952011. The right panel of Figure 14 shows that the reduction with respect to the mean (parabola) is evident during the period 1990-2011. Thus, the $\mathrm{CO}_{2}$ during the testing period exhibited an increasing emission rate that is larger than the linear but smaller than the quadratic rate and this phenomenon is clearly exhibited during the period 1990-2011.
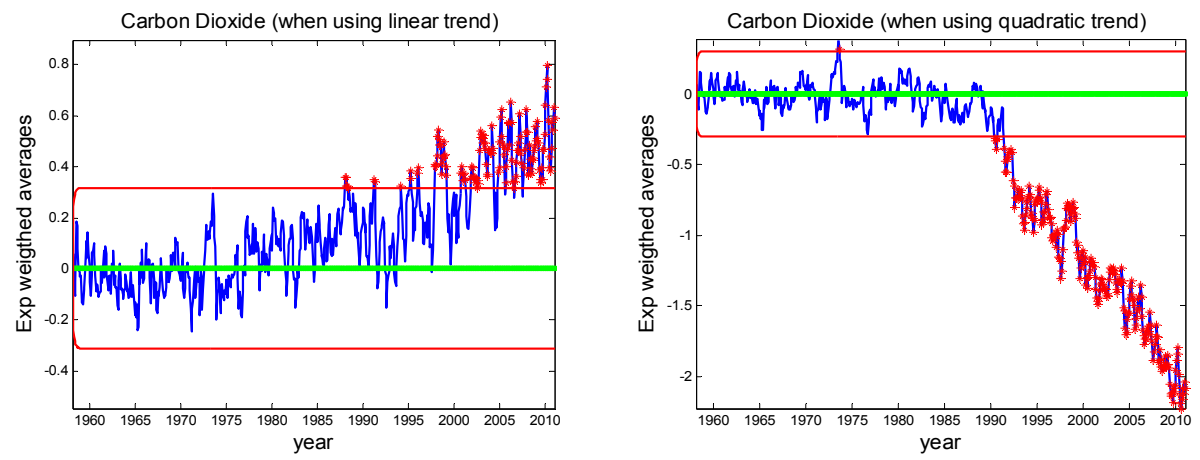

Fig. 14. The left panel shows that in 1988, the emissions of $\mathrm{CO}_{2}$ are larger than $0.0918 \mathrm{ppm}$ per month and this event becomes evident during 1995-2008. The right panel shows the relative reduction of concentration of $\mathrm{CO}_{2}$ when using a quadratic trend. The relative reduction occurred during 1992-2008.

\subsection{Climate indicators}

A climate indicator is a time series of a meteorological variable that contains the behaviour of a climate of the Earth and may exhibit a climate change. The selected climate indicators were the surface temperature, and cloud cover. The information contained in the climate 
indicators come from ground meteorological stations, satellite observations, and numerical weather prediction models.

\subsubsection{Global surface temperatures}

The global surface temperature is a climate indicator that has been used to show evidence that the Earth is warming and has become much stronger during recently years as reported in the Third Assessment Report (IPCC 2001). The IPCC (2007) also reported that from 19952006 were the warmest years since 1850 . The global surface temperatures were provided by the Goddard Institute for Space Studies (GISS), and include the period from January 1880 to December 2010. The surface data set was developed based on the Global Historical Climatology Network (GHCN). This analysis included observations from 6,300 ground stations located in different parts of the world (Hansen et al. 2010). Data from stations were confirmed with satellite data, and global climate model. Global temperature analyses are routinely either omitting urban stations or adjusting their long-term trends to try to eliminate or minimize the urban effect. The GISS analysis used 1951-1980 as the base period to develop the global temperature anomalies and the detailed description of data analysis is presented by Hansen et al. (2010). The monthly anomalies of the global land-ocean surface (AGLO) temperatures are shown in Figure 15, this product was selected because involves both the land and ocean measurements. These data were acquired at the web site http://data.giss. nasa.gov/gistemp/.

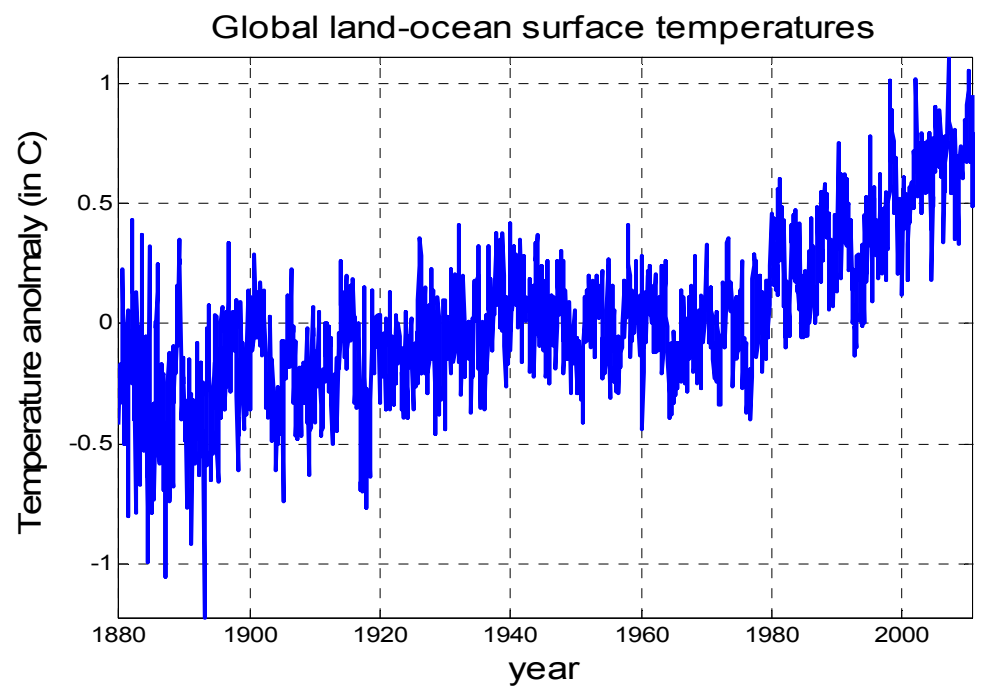

Fig. 15. Monthly anomalies of global land-ocean surface temperatures (1880-2010).

The AGLO temperatures were divided in two parts. The reference data includes the first one hundred years from January 1880 to December $1979(\mathrm{~m}=1200)$ and thirty-one years for the testing data from January 1980 to December 2010. The reference data show a significant linear trend with and increment of $0.00029^{\circ} \mathrm{C}$ per month. After removing the linear trend, the autocorrelation function and the periodogram were computed and it was found that this data do not include a significant periodic component, this is because that climatology was 
removed by GISS working group. The Autocorrelation function shows that the stochastic component can be represented by and $\operatorname{ARMA}(1,1)$.

Thus, the ARMA fingerprint can be computed as follows:

$$
\mathrm{f}_{\mathrm{t}}=\hat{\mathrm{s}}_{\mathrm{t}}-\tilde{\mathrm{s}}_{\mathrm{t}}
$$

where

$$
\begin{gathered}
\hat{\mathrm{s}}_{\mathrm{t}}=\mathrm{x}_{\mathrm{t}}-\widehat{\mathrm{T}}_{\mathrm{t}}=\mathrm{x}_{\mathrm{t}}+0.28-0.00029 \mathrm{t} \\
\tilde{\mathrm{s}}_{\mathrm{t}}=\left(\frac{1-0.4023 \mathrm{~B}}{1-0.827 \mathrm{~B}}\right) \tilde{\mathrm{a}}_{\mathrm{t}}
\end{gathered}
$$

The variable $x_{t}$ represents the AGLO temperatures; the standard deviation of $\tilde{a}_{t}$ for $t=$ $1, \ldots, \mathrm{m}$ was $0.169^{\circ} \mathrm{C}$. Figure 16 shows that the EWMA sequential test indicating a significant increment of AGLO temperature, which becomes evident in 1998. During the reference part (1880-1890), there are a few observations that exhibit some cooling behaviour or may be the presence of outliers.

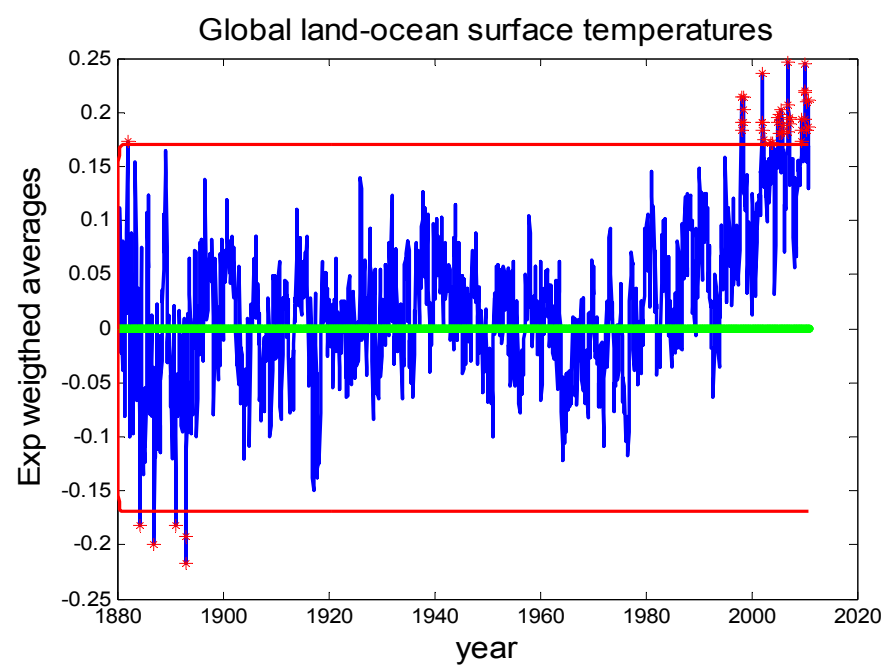

Fig. 16. The AGLO temperatures show a significant increment that becomes evident en 1998.

\subsubsection{Caribbean surface air temperatures}

Air temperatures for the major Caribbean islands were obtained from $\mathrm{GHCN}$ version 3. (ftp://ftp.ncdc.noaa.gov/pub/data/ghcn/v3/). The studied Caribbean islands are Cuba (CU), Jamaica (JA), Puerto Rico (PR), and La Espanola, which includes Dominican Republic (DR) and Haiti (HA). Table 3 shows the summary of stations that were used in this work. The monthly air temperature used in this analysis includes the following period: from January 1948 to February 2011. The quality of the data set was improved by removing inhomogeneities from the data record associated with non-climatic influences such as changes in instrumentation, and station environment (Peterson and Easterling, 1994). The monthly surface air temperatures from the National Center for Environmental Prediction 
(NCEP) reanalysis data were also used as a proxy variable to estimate some of the missing values that were encounter in some stations. The nearest grid point to each island was used to derive a regression equation between the temperature at a given station and the temperature of the nearest NCEP-grid-point. Regression equations exhibit an average of 0.9 of correlation coefficient between station temperature and NCEP data.

\begin{tabular}{|l|l|l|l|l|l|}
\hline Country & Cuba & $\begin{array}{l}\text { Dominican } \\
\text { Republic }\end{array}$ & Haiti & Jamaica & Puerto Rico \\
\hline $\begin{array}{l}\text { Number of } \\
\text { stations }\end{array}$ & 14 & 28 & 1 & 5 & 15 \\
\hline
\end{tabular}

Table 3. Number of stations over the Caribbean area.

Thirty years of data (from January 1948 to December 1977) were used to estimate climatology and anomalies; and after performing this calculations some of the data do not exhibit seasonal component. Figure 17 shows the monthly temperature anomalies for the major Caribbean islands from January 1948 to February 2011. Since Haiti provides only one station, the analysis for this country was omitted.

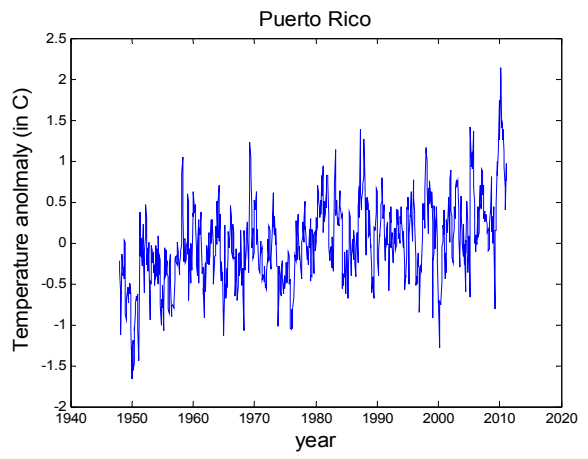

(a)

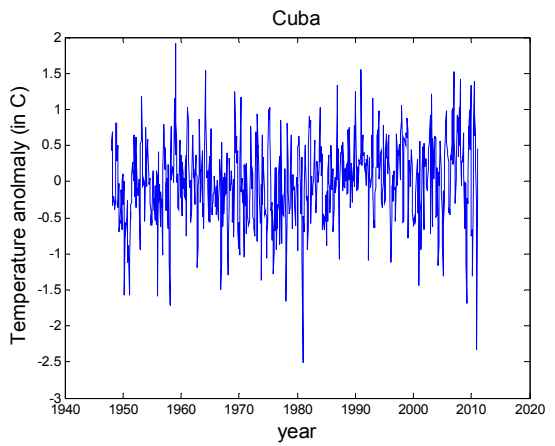

(c)

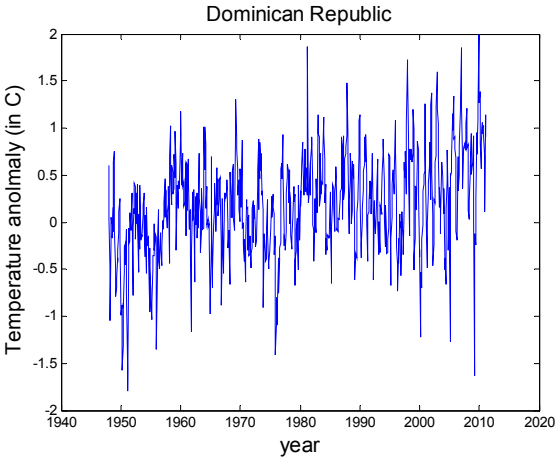

(b)

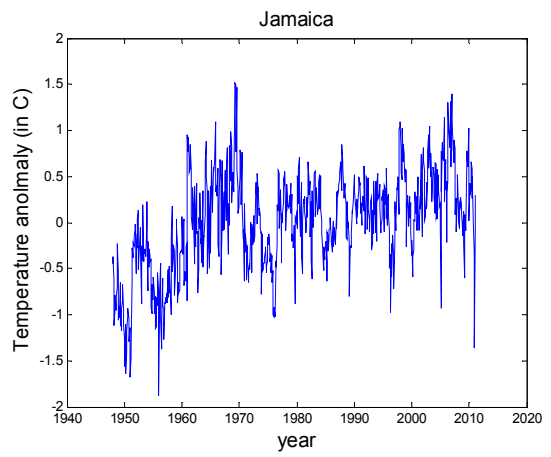

(d)

Fig. 17. Monthly temperature anomalies for the major Caribbean island. Data set includes observations from January 1948 to February 2011. 
The reference data of monthly anomalies for Puerto Rico exhibit a linear trend with an increasing rate of temperature of about $0.00095^{\circ} \mathrm{C}$ per month. The trend was removed and the periodicity component was very weak since climatology was subtracted from data; and consequently, this component was therefore deleted. The Autocorrelation function shows that the stochastic component can be represented by and autoregressive process (AR) of order one, AR(1). The AR process is a particular case of the ARMA model in which the moving average component is missing. The procedure to calculate the fingerprint is outlined in Table 4. The sequential statistical test was implemented to detect if there is any deviation from the mean. Figure 18a shows that Puerto Rico air temperatures indicate an additional increment in temperature that become evident in year 2010. This figure also shows some false alarms that occurred on 1988 and 2000. This pattern shows a weak climate-change signal over the island of Puerto Rico.

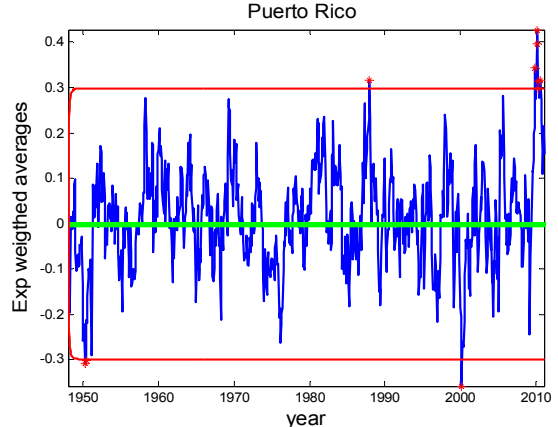

(a)

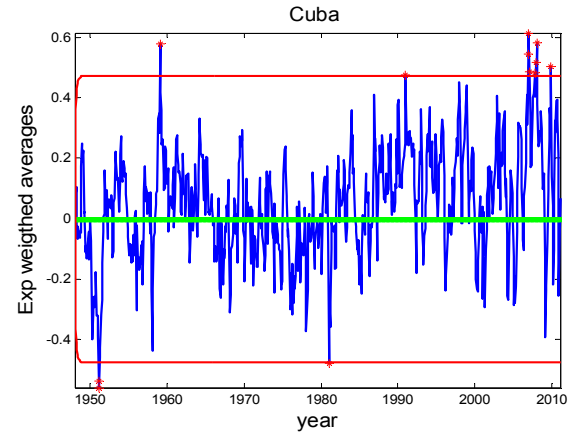

(c)

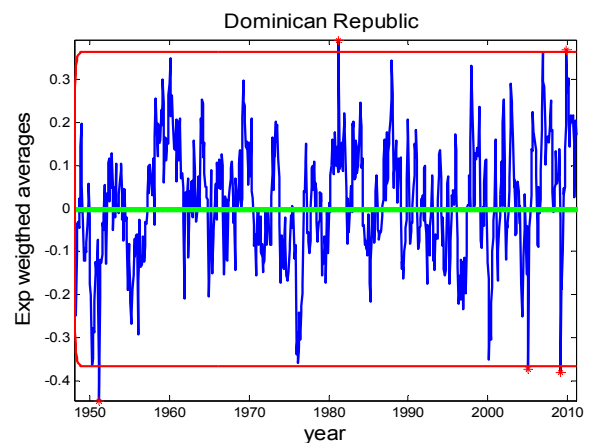

(b)

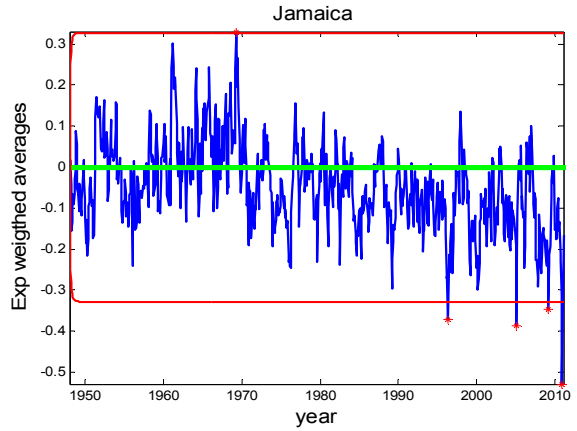

(d)

Fig. 18. a) This figure shows that in 2010 a significant climate change occurred in Puerto Rico. This figure also shows two false alarms occurred on 1988 and 2000; b) For Dominican Republic there was a significant trend during the reference data and no climate change during testing data, only a couple of false alarms occurred on 1981, 2005, 2009, and 2010; c) Cuba shows no trend during the reference data; however, there was a significant climate change that occurred during 2007-2010; d) Jamaica shows the largest trend during the reference data and a reduction on surface air temperature during the testing data, which indicates that the there were an over estimation of the linear trend during the reference data. 
The first thirty years of Dominican Republic were used to estimate climatology and also were used as the reference data (from January 1948 to December 1977). The reference data of temperature anomalies for Dominican Republic exhibit a linear trend with an increasing rate of about $0.00073^{\circ} \mathrm{C}$ per month. The harmonic analysis and the autocorrelation function show that there is a significant periodic component with period equal to 12 months. The stochastic component was computing after removing the trend and periodic component, as shown in Table 4. The autocorrelation function of the stochastic component shows that this process can be represented by an autoregressive (AR) process of orders one. Figure $18 \mathrm{~b}$ shows that there was no significant climate change for Dominican Republic. This figure also exhibits a couple of false alarms that occurred on the following years: 1981, 2005, 2009, and 2010.

\begin{tabular}{|c|c|c|}
\hline Component & Puerto Rico & Dominican Republic \\
\hline Fingerprint & $f_{t}=\hat{s}_{t}-\tilde{s}_{t}$ & $f_{t}=\hat{s}_{t}-\tilde{s}_{t}$ \\
\hline Stochastic & $\hat{\mathrm{s}}_{\mathrm{t}}=\mathrm{x}_{\mathrm{t}}-\widehat{\mathrm{T}}_{\mathrm{t}}$ & $\widehat{s}_{t}=x_{t}-\widehat{T}_{t}-\widehat{P}_{t}$ \\
\hline Trend & $\widehat{T}_{t}=-0.40+0.00095 t$ & $\widehat{T}_{t}=-0.1372+0.00073 t$ \\
\hline Periodic component & none & $\widehat{\mathrm{P}}_{\mathrm{t}}=-0.0057 \sin \left(\frac{2 \pi \mathrm{t}}{12}\right)-0.0054 \cos \left(\frac{2 \pi \mathrm{t}}{12}\right)$ \\
\hline Stochastic & $\tilde{s}_{t}=\left(\frac{1}{1-0.703 B}\right) \tilde{a}_{t}$ & $\tilde{s}_{t}=\left(\frac{1}{1-0.626 B}\right) \tilde{a}_{t}$ \\
\hline $\begin{array}{l}\text { standard deviation of } \\
\tilde{\mathrm{a}}_{\mathrm{t}}\end{array}$ & $0.30 \mathrm{C}$ & $0.36 \mathrm{C}$ \\
\hline Component & Cuba & Jamaica \\
\hline Fingerprint & $\mathrm{f}_{\mathrm{t}}=\hat{\mathrm{s}}_{\mathrm{t}}-\tilde{s}_{\mathrm{t}}$ & $f_{t}=\hat{s}_{t}-\tilde{s}_{t}$ \\
\hline Stochastic & $\widehat{s}_{t}=x_{t}-\widehat{P}_{t}$ & $\widehat{s}_{t}=x_{t}-\widehat{T}_{t}$ \\
\hline Trend & None & $\widehat{\mathrm{T}}_{\mathrm{t}}=-0.4998+0.00270 \mathrm{t}$ \\
\hline Periodic component & $\begin{array}{l}\widehat{\mathrm{P}}_{\mathrm{t}} \\
=-0.0103 \sin \left(\frac{2 \pi \mathrm{t}}{12}\right) \\
-0.0065 \cos \left(\frac{2 \pi \mathrm{t}}{12}\right)\end{array}$ & None \\
\hline Stochastic & $\tilde{s}_{t}=\left(\frac{1}{1-0.4248 B}\right) \tilde{a}_{t}$ & $\tilde{s}_{t}=\left(\frac{1-0.3753 \mathrm{~B}}{1-0.9071 \mathrm{~B}}\right) \tilde{\mathrm{a}}_{\mathrm{t}}$ \\
\hline $\begin{array}{l}\text { standard deviation of } \\
\tilde{\mathrm{a}}_{\mathrm{t}}\end{array}$ & $0.47 \mathrm{C}$ & $0.32 \mathrm{C}$ \\
\hline
\end{tabular}

Table 4. Calculations of the ARMA fingerprint for the major Caribbean islands.

As in the previous islands, the first thirty years were used to estimate climatology of the surface air temperature of Cuba. The reference data include monthly observations from January 1948 to December 1978. The anomalies of reference-data of air temperature from Cuba exhibit a no significant trend. The harmonic analysis and the autocorrelation function show that there is a significant periodic component with period equal 12 months. The autocorrelation function of the stochastic component shows that this process can be represented by an $\mathrm{AR}(1)$ process. Estimates of a sinusoidal function and the stochastic component are given in Table 4 . Figure $18 \mathrm{c}$ shows that there was a significant climate 
change occurred on Cuba and becomes evident during 2007 to 2010. This figure also shows that there are some false alarms that occurred on 1981, and 1991.

In Table 4 the variable $\mathrm{x}_{\mathrm{t}}$ represents the anomaly temperatures for the corresponding country, $B$ is back shift operator; $m=360$ and $n=758$.

The reference data of monthly anomalies for Jamaica exhibit a linear trend with an increasing rate of temperature of about $0.00270{ }^{\circ} \mathrm{C}$ per month. The trend was removed and periodicity component was not significant component. The autocorrelation function shows that the stochastic component can be represented by and $\operatorname{ARMA}(1,1)$. The fingerprint procedure is outlined in Table 4 and estimates are also given in this table. The sequential statistical test was implemented to detect an addition deviation from the mean in the testing data. Figure 18d shows that Jamaica air temperatures indicate there is a possible reduction with respect to the linear trend; i.e., there was an over estimation of the increasing rate given for a reference data. It should be noted that Jamaica during the first two decades (1948 to 1968) shows a significant increasing rate of temperature and caused an over estimation of trend during the reference data. Jamaica increasing rate is about three times higher than Puerto Rico and four times than Dominican Republic.

In summary, Jamaica exhibits the largest increasing rate of surface air temperature and this phenomenon occurred during 1948 to 1968. Cuba shows no increasing rate during the reference data; however, exhibits a significant increment during 2007 to 2010. Puerto Rico shows a linear trend during the reference data in addition to a significant increment of temperature in 2010. Dominican Republic shows a significant trend during the reference data and no more changes during the testing data. In general, the climate change exhibited in the Caribbean islands is marginal compared to a global scale.

\subsubsection{Global cloud cover}

The cloud cover monthly time series was obtained from the International Satellite Cloud Climatology Project (ISCCP). The cloud products were generated from sensors located on seven satellites, and the D2 product provides the properties of the clouds observed at every three hours and presented in monthly time series during the period of July 1983 to June 2005. Some of the included variables in this data set are cloud cover, top-cloud temperature, top-cloud pressure, optical thickness, and water path. The clouds are classified based on optical thickness and on top pressure. More information can be found in the following site: http://iridl.ldeo.columbia.edu/SOURCES/.NASA/.ISCCP/.D2/.all/. Quispe developed a user friendly computer program to read and manage the cloud data files.

The global cloud cover file includes 6,596 grids and the cloud cover was selected at global and at Caribbean scales. Figure 19 shows the global cloud cover.

Data from July 1983 to June 1994 were used as reference and from July 1994 to June 2005 as the testing data; the following values were selected for $n=264$ months, and $m=132$ months. A significant linear trend was identified and the harmonic analysis shows that there are three significant harmonics at 12, 132 and 66 months. Thus, the linear trend and the sinusoidal functions were removed from the original data and the stochastic process follows an AR(1) model. The estimates of the trend, the sinusoidal function, and stochastic model are given in Table 5. The left panel of Figure 20 shows the performance of the sequential test, which shows and an additional reduction of cloud cover that occurs during 1997 to 2001; however, increment was also detected from 2004 to 2005 and a possible false alarm occurs on 1994. With the purpose of better understanding the behaviour of the clouds, a second analysis was conducted without trend; i.e., in this case we want to measure the deviation 
with respect to the constant average of the reference data. The right panel of Figure 20 indicates that a significant reduction occurs with respect to the reference mean during 1995 to 2004. In summary, it can be concluded that a significant reduction of global cloud cover occurs and especially during the period of 1995 to 2004.

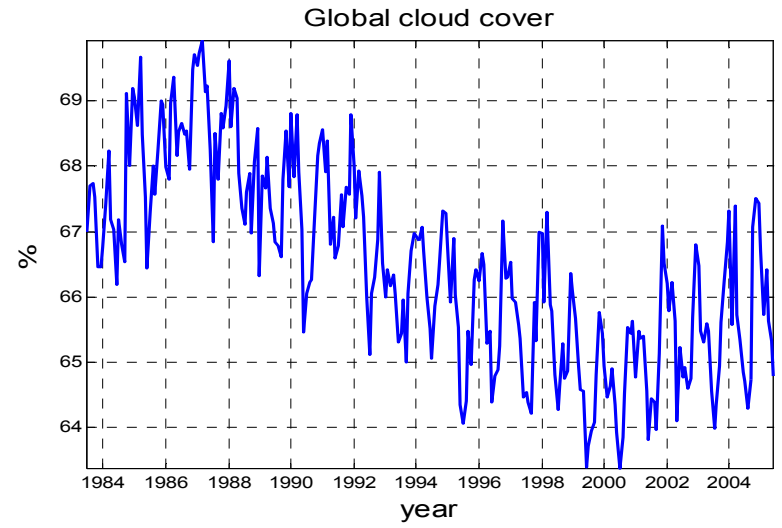

Fig. 19. Global cloud cover.
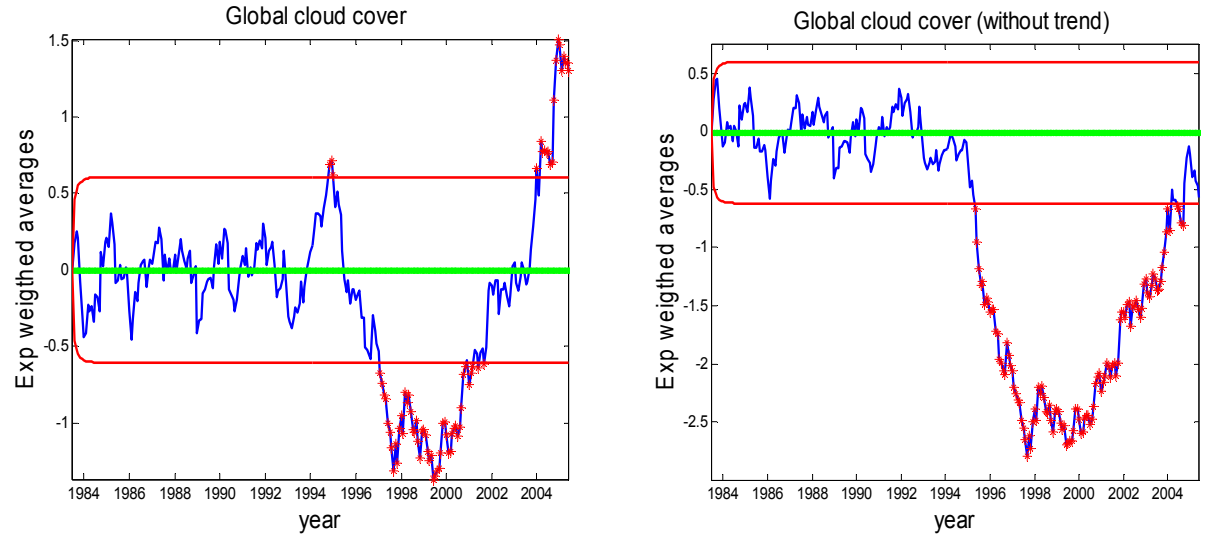

Fig. 20. The left panel shows that a significant reduction was detected during 1997 to 2001 . The right panel shows an analysis without trend, and confirmed that a significant reduction of global cloud cover occurred during 1995 to 2004.

\subsubsection{Caribbean cloud cover}

The selected Caribbean area includes the following geographical location: latitude from 17 $\mathrm{N}$ to $24 \mathrm{~N}$ and longitude from $87 \mathrm{~W}$ to $64 \mathrm{~W}$, as shown in Figure 21. The data was organized as follows: the reference data include from July 1983 to June 1994 and the testing data are from July 1994 to June 2005. The reference data exhibit a significant reduction rate $(-0.0259$ per month) of cloud cover and the harmonic analysis shows that there is a significant periodic function with period equal to twelve. The remaining stochastic component can be modelled by a moving average of order one; i.e., MA(1). This model is also a particular case of the ARMA model, in which the model does not contain the autoregressive part. The 


\begin{tabular}{|c|c|c|c|c|}
\hline Component & \multicolumn{4}{|c|}{ Global cloud cover } \\
\hline Fingerprint & \multicolumn{4}{|c|}{$\mathrm{f}_{\mathrm{t}}=\hat{\mathrm{s}}_{\mathrm{t}}-\tilde{s}_{\mathrm{t}}$} \\
\hline Stochastic & \multicolumn{4}{|c|}{$\widehat{s}_{t}=x_{t}-\widehat{T}_{t}-\widehat{P}_{t}$} \\
\hline Trend & \multicolumn{4}{|c|}{$\widehat{T}_{t}=68.49-0.0137 t$} \\
\hline \multirow{5}{*}{$\begin{array}{l}\text { Periodic } \\
\text { component }\end{array}$} & \multicolumn{4}{|c|}{$\widehat{\mathrm{P}}_{\mathrm{t}}=\sum_{\mathrm{i}=1}^{3} \hat{\mathrm{b}}_{\mathrm{i}} \sin \left(\frac{2 \pi \mathrm{t}}{\mathrm{p}_{\mathrm{i}}}\right)+\widehat{\mathrm{c}}_{\mathrm{i}} \cos \left(\frac{2 \pi \mathrm{t}}{\mathrm{p}_{\mathrm{i}}}\right)$} \\
\hline & $\mathrm{i}$ & $\hat{\mathrm{b}}_{\mathrm{i}}$ & $\widehat{c}_{i}$ & $\begin{array}{c}\mathrm{p}_{\mathrm{i}} \\
\text { (months) }\end{array}$ \\
\hline & 1 & -0.3819 & -0.5707 & 12 \\
\hline & 2 & 0.7968 & -0.625 & 132 \\
\hline & 3 & 0.0189 & -0.4304 & 66 \\
\hline Stochastic & \multicolumn{4}{|c|}{$\tilde{s}_{t}=\left(\frac{1}{1-0.2327 B}\right) \tilde{a}_{t}$} \\
\hline Standard deviation of $\tilde{a}_{t}$ & \multicolumn{4}{|c|}{0.605} \\
\hline
\end{tabular}

Table 5. Calculations for the ARMA fingerprint for the global cloud cover.

procedure to compute the fingerprint and the estimation of parameters are given in table 6 . The sequential test indicates that no additional change was found in the Caribbean cloud clover. Table 6 shows that Caribbean cloud cover during the reference data exhibit a reduction rate of $-0.0259 \%$ per month. Figure 22 Shows that Caribbean clouds cover no additional climate change is detected.

\begin{tabular}{|c|c|}
\hline Component & Caribbean cloud cover \\
\hline Fingerprint & $\mathrm{f}_{\mathrm{t}}=\widehat{\mathrm{s}}_{\mathrm{t}}-\widetilde{\mathrm{s}}_{\mathrm{t}}$ \\
\hline Stochastic & $\widehat{\mathrm{s}}_{\mathrm{t}}=\mathrm{x}_{\mathrm{t}}-\widehat{\mathrm{P}}_{\mathrm{t}}$ \\
\hline Trend & $\widehat{\mathrm{T}}_{\mathrm{t}}=52.76-0.0259 \mathrm{t}$ \\
\hline Periodic component & $\widehat{\mathrm{P}}_{\mathrm{t}}=5.4444 \sin \left(\frac{2 \pi \mathrm{t}}{12}\right)+2.869 \cos \left(\frac{2 \pi \mathrm{t}}{12}\right)$ \\
\hline Stochastic & $\widetilde{\mathrm{s}}_{\mathrm{t}}=(1+0.2263 \mathrm{~B}) \tilde{\mathrm{a}}_{\mathrm{t}}$ \\
\hline Standard deviation of $\tilde{\mathrm{a}}_{\mathrm{t}}$ & 5.99 \\
\hline
\end{tabular}

Table 6. Estimation of the fingerprint for the Caribbean cloud cover.

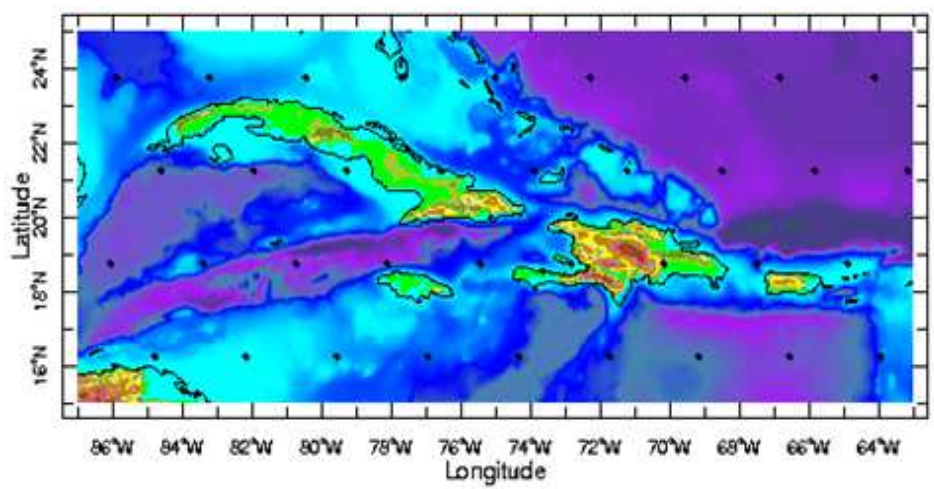

Fig. 21. The selected Caribbean region to be studied. 


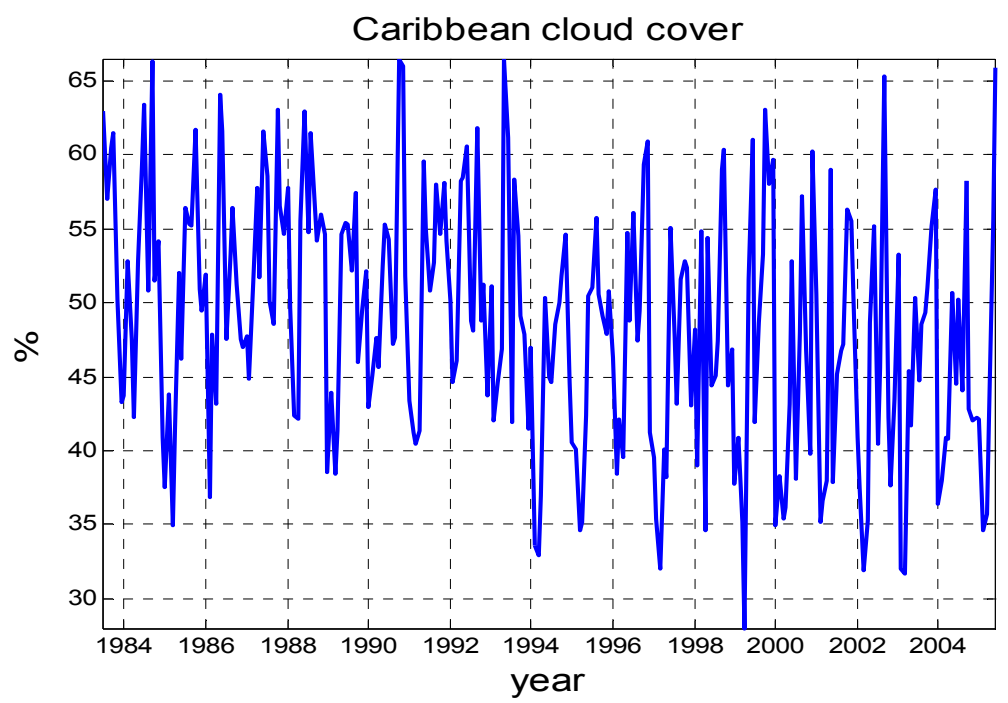

Fig. 22. The Caribbean clouds cover from July 1983 to June 2005. This data were extracted from ISCCP D2 using the Quispe (2006) program.

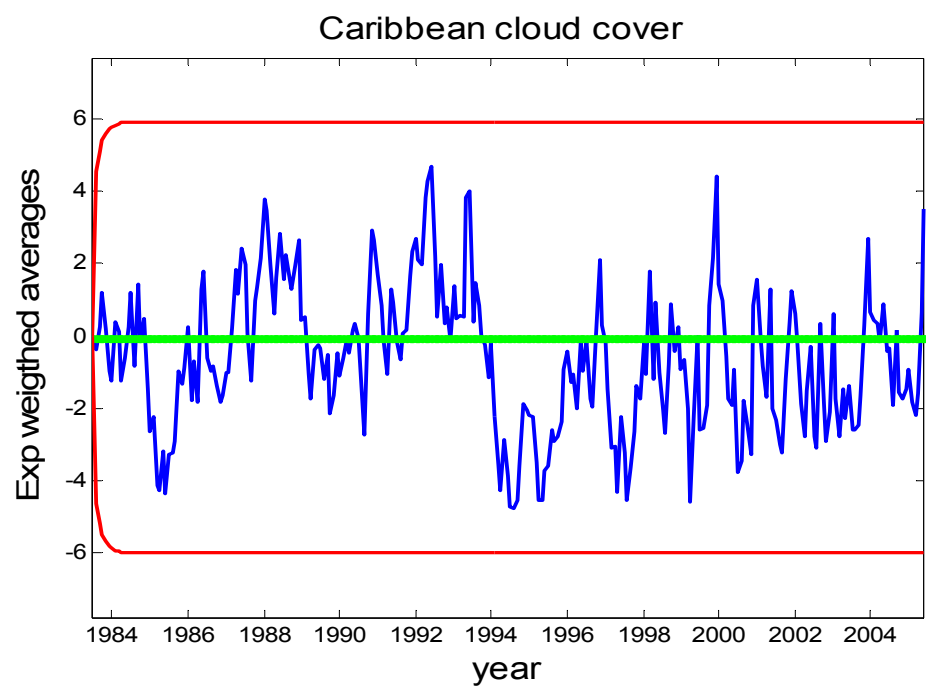

Fig. 23. Caribbean clouds cover shows a no additional reduction of cloud cover.

\section{Conclusion}

The major factors that have forced climate change are due to natural and anthropogenic causes such as solar radiation, volcano eruptions, increasing concentration of greenhouse gases, etc. A statistical test is proposed to detect when a significant climate change has 
occurred. Usually, a climate indicator can be decomposed into three major features: trend, seasonal, and stochastic component. A climate change can be exhibited in any of the components of a given climate indicator. The introduced statistical test detects a climate change that can be observed in any of the three component of the process. The test consists on dividing the underlying time series in two parts. The first part of the observations is used for identifying trend, seasonality and stochastic components and these components are removed from the entire time series. The test consists of determining whether or not the remaining part of the series exhibits a significant deviation from the white noise. Thus, if a significant deviation from the white noise process occurs a climate change is detected; otherwise, no change has recorded. The proposed test was implemented to detected climate changes at global and Caribbean levels. The studied variables were: sunspots, concentration of carbon dioxide, surface air temperature, and cloud cover. At the Caribbean levels, it was found that cloud cover exhibits a significant reduction rate whereas the air temperature shows a significant increasing rate. Rainfall processes across the main Caribbean islands shows no significant trend during the studied period, which suggests that heavy rainfall events are being concentrated in small areas to maintain the rainfall process with no trend. The global cloud cover also shows a significant decreasing trend whereas the land-ocean surface temperature shows an increasing trend. Smaller clouds cover areas and high temperatures across the world also suggests that heavy rainfall processes will be concentrated in small continental areas causing flooding, landslide, and human and economic catastrophic impacts.

A sequential statistical test has been introduced to detect when as significant climate change has occurred. The major contribution of this work is to introduce a statistical tool to determine without ambiguity when a climate change has occurred. One of the advantages of the proposed procedure is its simplicity; however, it requires of a large sequence of a reliable climate indicator, where a climate indicator is a meteorological variable that reveals the intrinsic climatic characteristic of a given region of the Earth. It is very important to understand the interaction of the physical processes and how the climate indicators are related. One of the major limitations of the proposed detection test is that some climate indicators after removing the trend and the periodic components still retain characteristics of a nonstationary process and difference operators to induce stationary behaviour are not applicable, since the difference operator not only removes the nonstationary behaviour but also remove the climate change.

\section{Acknowledgments}

This research has been supported by National Aeronautics and Space Administration (NASA) EPSCoR program with grant NCC5-595 and also by the University of Puerto Rico. Authors want to recognize the technical support from several institutions that provided the climate indicator variables.

\section{References}

Angeles-Malaspina, Moisés E. 2005. An Assessment of Future Caribbean Climate Change Using "Business as Usual" Scenario by Coupling GCM Data and RAMs. Thesis of Master of Science in Mechanical Engineering, University of Puerto Rico-Mayagüez Campus. 
Angeles, M.E. Gonzalez, E. J., Ericsson III, D. J., and Hernandez, J.L. (2006). Predictions of future climate change in the Caribbean region using global general circulation models. International Journal of Climatology, DOI: 10.1002/joc.1416

Barnett, T.P. Hasselman, K., M. Chelliah, T. Delworth, G. Hergel, P. Jones, E. Ramsmusson, E. Roeckner, C Ropelewski, B. Santer and S. Tett (1999), Detection and Attribution of Recent Climate Change: A Status Report, Bull. Am. Meteorol. Soc. Vol. 80 No. 12, December 1999.

Battisti D., Bitz M., Moritz R. (1997) Do General Circulation Models Underestimate the Natural Variability in the Arctic Climate? Journal of Climate, Vol. 10: 1909 1920.

Box G., and Jenkins (1976). Time Series Analysis Forecasting and Control. Golden-Day, California.

Brockwell, P. and Davis R. (2002), Introduction to Time Series and Forecasting, 2nd ed., Springer-Verlag New York, Inc.

Burroughs, W.J. (2001), Climate Change: A Multidisplinary Approach, 1st Edition, Cambridge University Press

Changnon S. A., Pielke R. A. Jr., Changnon D., Sylves R. T., and Pulwarty R., (2000) Human Factors Explain the Increased Losses from Weather and Climate Extremes; Bull. Am. Meteorol. Soc.; 81, 437 - 442.

Easterling D. R., Meehl G. A., Parmesan C., Changnon S. A., Karl T. R. and Mearns L. O. (2000) Climate Extremes: Observations, Modeling, and Impacts; Science, 289, 2068 2074.

Feldstein, S. B. (2002). The Recent Trend and Variance Increase of the Annular Mode, Journal of Climate, Vol. 15, 88-94.

Hansen, J., R. Ruedy, M. Sato, and K. Lo (2010), Global surface temperature change, Rev. Geophys., 48, RG4004, doi:10.1029/2010RG000345.

Hansen, J (2005). A slippery slope: How much global warming constitutes "dangerous anthropogenic interference"? Climatic Change, 68: 269-279.

Huntingford C., Stott P., Allen M., and Lambert H., (2006) Incorporating model uncertainty into attribution of observed temperature change, Geophys. Res. Lett., Vol. 33, L05710.

IPCC, Climate Change 2001: The Scientific Basic, Cambridge University Press, 697 738 pps.

IPCC - Climate Change: The Physical Science Basis 2007. Edited by Solomon, S., Qin, D., and Manning, M. Co-Chair, Co-Chair, Head, Technical Support Unit, IPCC Working Group I Melinda Marquis Kristen Averyt Melinda M.B. Tignor Henry LeRoy Miller, Jr.

Keeling, D. and Whorf T. (2005). Atmospheric $\mathrm{CO}_{2}$ records from sites in the SIO air sampling network. In Trends: A Compendium of Data on Global Change. Carbon Dioxide Information Analysis Center, Oak Ridge National Laboratory, U.S. Department of Energy, Oak Ridge, Tenn., U.S.A. Available in wet site: http://cdiac.ornl.gov/trends/co2/sio-mlo.htm 
Leuliette, E. , R. Nerem, and G. Mitchum, (2004). Calibration of TOPEX/Poseidon and Jason altimeter data to construct a continuous record of mean sea level change. Marine Geodesy, 27(1-2), 79-94.

MathWorks, 2000: Optimization Toolbox for use with Matlab: User's Guide. The MathWorks, Inc.

Meehl G., Washington W., Ammann C., Arblaster J., Wigley T., and Tebaldi C., (2004), Combinations of Natural and Anthropogenic Forcings in Twentieth-Century Climate, Journal of Climate, Volume 17: 3721 - 3727.

Menne, Matthew J., (2005), Abrupt Global Temperature Change and the Instrumental Record, $18^{\text {th }}$ Conference on Climate Variability and Change, P4.3.

Montgomery, D. (2001), Introduction to Statistical Quality Control, 4th Edition, John Wiley \& Sons, Inc.

Nicolay, S., Mabille, G., Ferrweis, X., and Erpicum, M., (2010). Multi-months cycles observed in climatic data. Climate Change and Variability Edited by Suzanne W. Simard and Mary E. Austin Published by Sciyo Janeza Trdine 9, 51000 Rijeka, Croatia. ISBN 978-953-307-144-2.

Pandit, S.M. and Wu, S.M 1983. Time Series and System Analysis with Applications, 1st Edition, John Wiley \& Sons, Inc.

Peterson, T.C., and D.R. Easterling, 1994: Creation of homogeneous composite climatological reference series. International journal of climatology, 14 (6), 671-679.

Quispe, W. (2006). Sieve Bootstrap en Series de Tiempo de Nubosidad en el Caribe. Thesis Master of Science in Mathematics, University of Puerto Rico, Mayagüez, 165 pages.

Ramirez-Beltran, N. D., and Sastri, T. (1997), Transient Detection With An Aplication To A Chemical Process, Computer ind. Engng Vol. 32, No. 4, pp. 891-908.

Roberts, S. W. (1959). Control Chart Tests Based on Geometric Moving Average. Technometrics, Vol 1.

Robock A. (2000). Volcanic Eruptions and Climate, Reviews of Geophysics, 38, 2: 191219.

Salinger, M. J. (2005), “Climate Variability and Change: Past, Present and Future - an overview", Climate Change 70: 9-29.

Santer B. D., Wigley T. M. L., Mears C., Wentz F. J, Klein S. A., Seidel D. J., Taylor K. E., Thorne P. W., Wehner M. F., Gleckler P. J., Boyle J. S., Collins W. D., Dixon K. W., Doutriaux C., Free M., Fu Q., Hansen J. E., Jones G. S., Ruedy R., Karl T. R., Lanzante J. R., Meehl G. A., Ramaswamy V., Russell G. and Schmidt G. A., (2005) Amplification of Surface Temperature Trends and Variability in the Tropical Atmosphere, Science, 309: 1551 - 1556.

Schar C, Vidale Pl, Luthi D, Frei C, Haberli C, Liniger MA, and C. Appenzeller, (2004); The role of increasing temperature variability in European summer heatwaves; Nature, 427: 332-335.

Smith R., Wigley T. and Santer B. (2002), A Bivariate Time Series Approach to Anthropogenic Trend Detection in Hemispheric Mean Temperatures. Journal of Climate, 16: 1228 - 1240.

Stott P. and Kettleborough J., (2002). Origins and estimates of uncertainty in predictions of twenty-first century temperature rise, Nature, Vol. 416: 723 - 726. 
She C., Krueger D., (2004), Impact of natural variability in the 11-year mesopause region temperature observation over Fort Collins, CO (41_N, 105_W), Advances in Space Research, Vol. 34, 330-336.

Tomé, A. R., and P. M. A. Miranda (2004), Piecewise linear fitting and trend changing points of climate parameters, Geophys. Res. Lett., 31, L02207, doi:10.1029/ 2003GL019100

Wei, W.W.S (1990), Time Series Analysis: Univariate and Multivariate Methods, 1st Edition, Addison-Wesley Publishing Company

http://www.statgraphics.com/downloads.htm

http://www.minitab.com/en-US/default.aspx

http://www.mathworks.com/ 


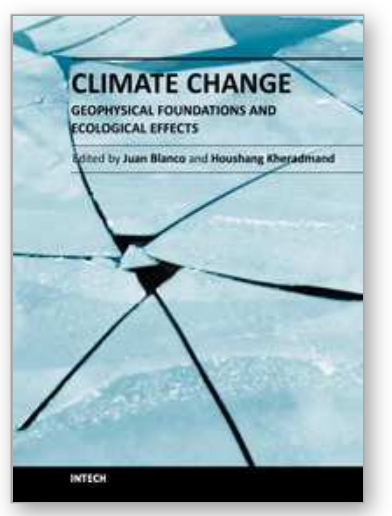

\author{
Climate Change - Geophysical Foundations and Ecological Effects \\ Edited by Dr Juan Blanco
}

ISBN 978-953-307-419-1

Hard cover, 520 pages

Publisher InTech

Published online 12, September, 2011

Published in print edition September, 2011

This book offers an interdisciplinary view of the biophysical issues related to climate change. Climate change is a phenomenon by which the long-term averages of weather events (i.e. temperature, precipitation, wind speed, etc.) that define the climate of a region are not constant but change over time. There have been a series of past periods of climatic change, registered in historical or paleoecological records. In the first section of this book, a series of state-of-the-art research projects explore the biophysical causes for climate change and the techniques currently being used and developed for its detection in several regions of the world. The second section of the book explores the effects that have been reported already on the flora and fauna in different ecosystems around the globe. Among them, the ecosystems and landscapes in arctic and alpine regions are expected to be among the most affected by the change in climate, as they will suffer the more intense changes. The final section of this book explores in detail those issues.

\title{
How to reference
}

In order to correctly reference this scholarly work, feel free to copy and paste the following:

Nazario D. Ramirez-Beltran, Joan Manuel Castro and Oswaldo Julca (2011). Detecting of a Global and Caribbean Climate Change, Climate Change - Geophysical Foundations and Ecological Effects, Dr Juan Blanco (Ed.), ISBN: 978-953-307-419-1, InTech, Available from: http://www.intechopen.com/books/climatechange-geophysical-foundations-and-ecological-effects/detecting-of-a-global-and-caribbean-climate-change

\section{INTECH}

open science | open minds

\section{InTech Europe}

University Campus STeP Ri

Slavka Krautzeka 83/A

51000 Rijeka, Croatia

Phone: +385 (51) 770447

Fax: +385 (51) 686166

www.intechopen.com

\section{InTech China}

Unit 405, Office Block, Hotel Equatorial Shanghai

No.65, Yan An Road (West), Shanghai, 200040, China

中国上海市延安西路65号上海国际贵都大饭店办公楼 405 单元

Phone: +86-21-62489820

Fax: $+86-21-62489821$ 
(C) 2011 The Author(s). Licensee IntechOpen. This chapter is distributed under the terms of the Creative Commons Attribution-NonCommercialShareAlike-3.0 License, which permits use, distribution and reproduction for non-commercial purposes, provided the original is properly cited and derivative works building on this content are distributed under the same license. 